University of Wollongong

Research Online

Faculty of Engineering and Information

Faculty of Engineering and Information

Sciences - Papers: Part A

Sciences

$1-1-2013$

\title{
Estimation of the compression behaviour of reconstituted clays
}

Martin D. Liu

University of Wollongong, martindl@uow.edu.au

Ziling Zhuang

University of Wollongong

Suksun Horpibulsuk

Suranaree University of Technology, suksun@g.sut.ac.th

Follow this and additional works at: https://ro.uow.edu.au/eispapers

Part of the Engineering Commons, and the Science and Technology Studies Commons

Research Online is the open access institutional repository for the University of Wollongong. For further information contact the UOW Library: research-pubs@uow.edu.au 


\title{
Estimation of the compression behaviour of reconstituted clays
}

\begin{abstract}
The void index is a relative quantity measuring the position of the current void ratio of a clay against the void ratios of the clay at two specific vertical effective stresses (i.e., $\sigma v^{\prime}=100 \mathrm{kPa}$ and $\sigma \mathrm{v}^{\prime}=1000 \mathrm{kPa}$ ). Based on this concept, a simple systematic tool is proposed for estimating the compression behaviour of reconstituted clays over a wide range of stresses and water contents. Following the practice of geotechnical engineering computation, the compression behaviour of clays is idealised as linear segments in the IV Inp' (or the void index and the mean effective stress) space. Considering the variation in the available data, there are three related but independent models for describing the compression behaviour of reconstituted clays. The accuracy of estimation increases with the level of available data. The proposed estimation is used to simulate the behaviour of a variety of reconstituted clays over a wide range of stresses and water contents. With different levels of available data, the estimation is evaluated on the basis of these simulations. The proposed estimation can take maximumuse of available data and provide a simple yet practical tool for calculating the compression behaviour of reconstituted clays and a basic parameter for geotechnical engineering computations, the compression index. An empirical equation for the initial compression index is also suggested and verified.
\end{abstract}

\section{Keywords}

compression, behaviour, reconstituted, estimation, clays

Disciplines

Engineering | Science and Technology Studies

\section{Publication Details}

Liu, M. D., Zhuang, Z. \& Horpibulsuk, S. (2013). Estimation of the compression behaviour of reconstituted clays. Engineering Geology, 167 (December), 84-94. 


\title{
ESTIMATION OF THE COMPRESSION BEHAVIOUR OF RECONSTITUTED CLAYS
}

\author{
Martin D. Liu, B.Eng., M.Phl., Ph.D. \\ Senior Lecturer, Faculty of Engineering \\ University of Wollongong \\ NSW 2522, Australia, Email: martin@uow.edu.au \\ Tel: + 612 4221-3035; Fax: + 612 4221-3238
}

Ziling Zhuang, B.Eng. BE student, Faculty of Engineering University of Wollongong NSW 2522, Australia, Email: Zz770@uowmail.edu.au Tel: + 612 4221-3035; Fax: + 612 4221-3238

Suksun Horpibulsuk, B.Eng.(Hons), M.Eng., Ph.D. Professor and Chair, School of Civil Engineering, Head, Center of Excellence in Civil Engineering, Suranaree University of Technology, 111 University Avenue, Muang District, Nakhon Ratchasima 30000, THAILAND Tel: +66-44-22-4322 and +66-89-767-5759, Fax: +66-44-22-4607 Email: suksun@g.sut.ac.th and suksun@sut.ac.th

Date written: July 13, 2013

Number of words: 6419

NOTE: The third author is the corresponding author. Please address mail communication to Prof. Suksun Horpibulsuk, School of Civil Engineering, Suranaree University of Technology, 111 University Avenue, Muang District, Nakhon Ratchasima 30000, THAILAND 


\section{Estimation of the compression behaviour of reconstituted clays}

by

M. D. Liu ${ }^{1}$, Ziling Zhuang ${ }^{2}$, S. Horpibulsuk ${ }^{3 *}$

${ }^{1}$ Faculty of Engineering

The University of Wollongong

NSW 2522, Australia

martindl@uow.edu.au

${ }^{2}$ Faculty of Engineering

The University of Wollongong

NSW 2522, Australia

Zz770@uowmail.edu.au

${ }^{3}$ School of Civil Engineering

Suranaree University of Technology

Nakhon-Ratchasima, Thailand

suksun@g.sut.ac.th

\section{ABSTRACT}

The void index is a relative quantity measuring the position of the current void ratio of a clay against the void ratios of the clay at two specific vertical effective stresses, i.e., $\sigma^{\prime}{ }_{v}=100 \mathrm{kPa}$ and $\sigma^{\prime}{ }_{v}=1000 \mathrm{kPa}$.). Based on this concept, a simple systematic tool is proposed for estimating the compression behaviour of reconstituted clays over a wide range of stresses and water contents. Following the practice of geotechnical engineering computation, the compression behaviour of clays is idealised as linear segments in the $I_{v} \sim \ln p^{\prime}$ (or the void index and the mean effective stress) space. Considering the variation in the available data, there are three related but independent models for describing the compression behaviour of reconstituted clays. The accuracy of estimation increases with the level of available data. The proposed estimation is used to simulate the behaviour of a variety of reconstituted clays over a wide range of stresses and water contents. With different levels of available data, the estimation is evaluated on the basis of these simulations. The proposed estimation can take maximum use of available data and provide a simple yet practical tool for calculating the compression behaviour of reconstituted clays and a basic parameter for geotechnical engineering computations, the compression index. An empirical equation for the initial compression index is also suggested and verified.

Keywords: Clay, compressibility, constitutive equations, reconstituted soil. 


\section{1. Introduction}

81 Compression behaviour is a fundamental aspect of soil deformation, and modelling

82 compression behaviour generally forms the base of modelling the stress-strain relationships 83 of soils (e.g., Pestana and Whittle, 1995; Hong and Onitsuka, 1998; Potts and Zdravkovic 84 1999; Baudet and Stallebrass, 2001; Liu et al, 2011). Many practical geological and 85 geotechnical engineering problems are often analysed based on soil properties determined 86 from compression tests as key parameters. One example is the settlement computations of the

87 surface of land, which can be induced by various factors such as the change of the levels of 88 ground water, mining activities, mud flow, sedimentation, and earthquakes. . The 89 understanding of compression behaviour has therefore always been important to geological 90 and geotechnical engineering practice and research for many decades (e.g., Skempton, 1944;

91 Bowles, 1989; Butterfield and Baligh, 1996; Desai, 2001; and Chai et al, 2004).

92 The inherent nature and diversity of the geotechnical process involved in soil formation are

93 responsible for the compressibility of soils. The stresses to which soils have been subjected,

94 the environments in which they are formed and the time that has lapsed on the geotechnical

95 time scale over different stages of their formation have been recognised as potential factors in 96 their compressibility. Soils age and creep over time; hence, bonds develop at particle 97 contacts in natural clay, which can also be thought of as "structured clay" (Leonards, 1972;

98 Leroueil et al., 1979; Michell, 1996; and Shibuya, 2000; etc.). The term "soil structure" refers

99 to the particle associations and arrangements (fabric) and to inter-particle forces. The 100 resistance of soil structure is responsible for the difference in the engineering behaviour of 101 natural soils between the structured and the destructured (reconstituted) states (Leroueil et al., 1021979 and 1983; Hanzawa and Adachi, 1983; Leroueil and Vaughan, 1990; Mitchell, 1996; 103 and Shibuya, 2000). The development of a soil structure during depositional and 
104 postdepositional processes has been documented by many researchers (Locat and Lefebvre, 105 1985; Mitchell, 1986; and Schmertmann, 1991). The compression curve of reconstituted clay 106 is intrinsic (devoid of soil structure) and is usually used as a frame of reference for the 107 behaviour of naturally and artificially structured soils (Burland, 1990; Nagaraj and Miura, 108 2001; Nagaraj et al., 1990 and 1998) and as a basis for modelling the behaviour of soils in the 109 structured state (e.g., Liu et al, 2000; Masín, 2007; Hinchberger and Qu, 2009; Horpibulsuk 110 et al, 2007, 2010; 2013; Suebsuk et al., 2010 and 2011). Moreover, reconstituted clay is 111 typical used as a liner for landfill and a fill for reclaimed area, and the compressibility of the 112 reconstituted clay is one of the required design parameters.

113 Burland (1990) proposed the concept of void index and demonstrated its ability to generalise 114 the compression behaviour of reconstituted clays and the influence of natural soil structure.

115 The concept has since been used widely in interpreting the compression behaviour of 116 structured soils (e.g., Low et al, 2008; and Horpibulsuk et al, 2011). Based on Burland's work 117 and many others, a further study is presented in this paper focusing on reconstituted clays.

118 A systematic tool is proposed for estimating the compression behaviour of reconstituted clays 119 over a wide range of stresses and water contents in the void index $I_{v}$ and mean effective stress $120 p^{\prime}$ space, i.e., the $I_{v} \sim \ln p^{\prime}$ space. The objective of this study is to provide an estimation of the 121 void ratio and compression index of clays during compression over a wide range of stress 122 levels, from $1 \mathrm{kPa}$ to $100,000 \mathrm{kPa}$, with the flexibility of implementing various levels of 123 available data. The compression indexes in the $e \sim \log \sigma^{\prime}{ }_{v}$ space and the $e \sim \log p^{\prime}$ space are 124 essentially the same because their pattern similarity is widely observed (a discussion on the 125 two curves can be found in a paper by Liu and Carter, 1999). Some numerical difference in $126 \sigma^{\prime}{ }_{v}$ exists, but this difference is minimised by the normalisation. Values of $I_{v}=0$ for $100 \mathrm{kPa}$ 
127 and $I_{v}=-1$ for $1000 \mathrm{kPa}$ are observed in both cases. The proposed model is evaluated based 128 on comparisons between model performance and experimental data.

130 2. Estimation of the compression behaviour of reconstituted $131 \quad$ clays

\section{$132 \quad 2.1$ Burland's work on the compression behaviour of reconstituted soils}

133 In his fortieth Rankine lecture, Burland (1990) introduced the concept of void index and 134 performed a systematic study on the compression behaviour of clays via the void index. The 135 current research is carried out based on Burland's original work and subsequent research by 136 others (e.g., Amorosi and Rampello, 2007; Bobet et al, 2011; Hong et al, 2012). A change in

137 approach is made in the current study: the behaviour of soil is described by the mean

138 effective stress $p^{\prime}$, not the vertical effective stress, $\sigma^{\prime}{ }_{v}$. To distinguish between soil parameters

139 associated with $p^{\prime}$ and those associated with $\sigma^{\prime}{ }_{v}$, parameters associated with $\sigma^{\prime}{ }_{v}$ are indicated

140 by an italic and subscript $\mathrm{v}$. Hence, $e_{v}$ indicates the void ratio associated with the vertical

141 effective stress. For two parameters introduced in this study, differences exist between the 142 parameters used in the two systems: the parameters $e_{100}^{*}$ (the void ratio of the soil in a 143 reconstituted state at $p^{\prime}=100 \mathrm{kPa}$ ) and $e_{1000}^{*}$ (the void ratio at $p^{\prime}=1,000 \mathrm{kPa}$ ). For the

144 vertical effective stress, $\sigma_{v}^{\prime}$, the corresponding values are denoted as $e_{v, 100}^{*}, e_{v, 1000}^{*}$ and $C_{c, v}{ }^{*}$.

145 However, the value of the numeric difference between $e_{100}^{*}$ and $e_{1000}^{*}$, i.e., $C_{c}^{*}$, is the same as 146 that between $e_{100, v}^{*}$ and $e_{1000, v}^{*}$, i.e., $C_{c, v}{ }^{*}$. 
147 The void index $I_{v}$ is the relative magnitude of the void ratio calculated with the respect to the

148 void ratio of the soil in the reconstituted state at $p^{\prime}=100 \mathrm{kPa}$ and at $p^{\prime}=1,000 \mathrm{kPa}$, as shown

149 below,

$150 \quad I_{v}=\frac{e-e_{100}^{*}}{e_{100}^{*}-e_{1000}^{*}}=\frac{e_{v}-e_{v, 100}^{*}}{e_{v, 100}^{*}-e_{v, 1000}^{*}}$.

151 The properties of a reconstituted soil are referred to as intrinsic properties and are denoted by

152 the symbol ${ }^{*}$ attached to the relevant symbols. The parameter $C_{c}{ }^{*}$ is used to represent the

153 difference between $e_{100}^{*}$ and $e_{1000}^{*}$, i.e.,

$154 C_{c}^{*}=e_{100}^{*}-e_{1000}^{*}$.

155 Consequently, the void ratio and the void index are related by the following equation

$156 e^{*}=I_{v} C_{c}^{*}+e_{100}^{*}$

157 Burland proposed the following equations to describe the compression behaviour of 158 reconstituted soils (Fig. 1):

$I_{v}=2.45-1.285 \log \sigma_{v}^{\prime}+0.015\left(\log \sigma_{v}^{\prime}\right)^{3}$.

160 This line is the intrinsic compression line of soil and it is the same for both isotropic 161 compression tests and one-dimensional compression tests. To distinguish this line from the

162 widely used isotropic compression line $\mathrm{ICL}^{*}$ in the $e \sim \ln p^{\prime}$ space, this intrinsic void index

163 compression line is denoted by $\mathrm{I}_{\mathrm{v}} \mathrm{CL}^{*}$. As observed in Fig. 1, the $\mathrm{I}_{\mathrm{v}} \mathrm{CL}^{*}$ is curved in the $164 I_{v} \sim \ln \sigma^{\prime}{ }_{v}$ space.

165 A set of empirical equations are also proposed by Burland for estimating $e_{v, 100}^{*}$, and $e_{v, 1000}^{*}$ as 166 functions of the liquid limit void ratio, $e_{L}$. 
167

$e^{*}{ }_{v, 100}=0.109+0.679 e_{L}-0.089 e_{L}^{2}+0.016 e_{L}^{3}$,

$168 e_{v, 1000}^{*}=e_{v, 100}-0.256 e_{L}+0.04$.

169 Based on the theoretical framework of the critical state soil mechanics, the following

170 approximation can be made for $e_{100}^{*}$ and $e_{1000}^{*}$.

$171 \quad e^{*}{ }_{100}=e^{*}{ }_{v, 100}+\Delta$,

$172 e^{*}{ }_{1000}=e^{*}{ }_{v, 1000}+\Delta$,

173 where $\Delta$ is given by

$174 \Delta=\left(\frac{C_{c, v}{ }^{*}}{3}\right) \ln \left\{\left(1-\frac{2}{3} \sin \varphi_{c s}\right)\left[1+\left(\frac{3-\sin \varphi_{c s}}{6-4 \sin \varphi_{c s}}\right)^{2}\right]\right\}$

175 where $\varphi_{c s}$ is the critical-state friction angle measured in a triaxial compression test. If the

176 value of $\varphi_{c s}$ is not known, $\varphi_{c s}=20^{\circ}$ may be assumed. The method for the determination of $\Delta$

177 is similar to that for the void ratio at $p^{\prime}=1 \mathrm{kPa}$ from a one-dimensional compression test

178 (e.g., Muir-Wood, 1990; Liu and Carter, 2002).

\section{$179 \quad 2.2$ Experimental data}

180 A summary of a large amount of experimental data is shown in Fig. 2. Some detailed

181 information on the soils and the references are listed in Tables 1 and 2. These data were

182 obtained from 68 tests on 25 reconstituted clays and 45 tests on four clays in reconstituted

183 states but at various water contents. The following features of the compression behaviour of

184 the reconstituted clays are observed.

185 (1) The virgin compression behaviour of a reconstituted clay with a given mineralogy and 186 water content has been successfully normalised into one unique line with less 
dependence on the testing stress path. The compression behaviour of soil normalised by $I_{v}$ is graphically identical for the $I_{v} \sim \ln p^{\prime}$ space and for the $I_{v} \sim \ln \sigma^{\prime}{ }_{v}$ space. In this study, the soil behaviour in the $I_{v} \sim \ln p^{\prime}$ space is described.

(2) The virgin compression line for different reconstituted clays can be reasonably normalized into one unique linear line in the region of approximately 100 $\mathrm{kPa}<p^{\prime}<1,000 \mathrm{kPa}$.

(3) Based on the physical meaning of void in soils and the experimental observations, it is obvious that this linearity of soil behaviour does not hold for all possible values of $p^{\prime}$. mineralogy and water content of the soil.

198 The main objective of this study is to propose a simple tool for the prediction of the void ratio and compression index of soil with consideration of the curvatures at the two ends when there are available data.

\subsection{Proposed tool for estimation}

202 Based on the above observation, a systematic tool is proposed to provide a simple way to estimate the compression behaviour of reconstituted clays over a wide range of stresses, i.e.,

204 for $1 \mathrm{kPa} \leq p^{\prime} \leq 100,000 \mathrm{kPa}$, with the flexibility of application for various levels of available data. For geotechnical engineering computation of settlement and consolidation and for constitutive modelling, parameters that describe the deformation of soil are usually obtained

207 by assuming that the compression behaviour is linear in the $e \sim \ln p^{\prime}$ space (e.g., Desai and

208 Toth, 1996; Liu and Carter, 2000; Horpibulsuk et al., 2010; Suebsuk et al 2010, 2011; Chai and Carter 2011). Therefore, soil behaviour is idealised by linear segments, indicating that 
210 relevant soil parameters are dependent on the stress level. As a result, soil parameters

211 obtained from the proposed method can be used for direct engineering calculation.

212 The minimum datum for using the model is $e$. The following data, if available, can be used in 213 the model:

214 (1) $e_{100}^{*}$ : the void ratio of the soil in a reconstituted state at $p^{\prime}=100 \mathrm{kPa}$;

215 (2) $e_{1000}^{*}$ : the void ratio of the soil in a reconstituted state at $p^{\prime}=1,000 \mathrm{kPa}$;

$216 \quad(3)\left(e^{*}, p^{\prime}{ }_{i}\right)$ : an initial soil state;

217 (4) $p_{y}^{\prime}$ : the yielding mean effective stress or the maximum historical stress;

218 (5) $\kappa_{i}$ : the initial compression index (i.e., the gradient of the initial virgin compression

$219 \quad$ curve in the the $I_{v} \sim \ln p^{\prime}$ space);

220 (6) $\kappa_{e}$ : the ending compression index (i.e., the gradient of the compression curve for $p^{\prime}>5000 \mathrm{kPa}$ in the the $I_{v} \sim \ln p^{\prime}$ space);

(7) $\kappa_{u}$ : the swelling index (i.e., the gradient of the unloading and reloading curve in the the $I_{v} \sim \ln p^{\prime}$ space).

224 Any of the above seven groups of data can be incorporated into the proposed tool. It is obvious that the accuracy of estimation increases as more data are available. Three related but independent models for the estimation are proposed based on the available data. As shown in

227 Figs 2 and 3, the basic part of the estimation is the approximation of a unique bi-linear segments $\mathrm{OAB}$ : the compression line $\left(\mathrm{ICL}^{*}\right)$. The mean effective stress at the turning point $\mathrm{A}$ is $5,000 \mathrm{kPa}$. The gradient for line $\mathrm{OA}$ is 0.4343 , and the gradient for $\mathrm{AB}$ is a quarter of the

230 value of that for $\mathrm{OA}$, i.e., 0.1086. $\mathrm{OAB}$ or $\mathrm{ICL}^{*}$, the intrinsic compression line for 231 reconstituted clays, is defined as follows: 
$232\left\{\begin{array}{l}I_{v}=2-0.4343 \ln p^{\prime} \text { for } p^{\prime} \leq 5000 \mathrm{kPa} \\ I_{v}=-0.775-0.1086 \ln p^{\prime} \text { for } p^{\prime}>5000 \mathrm{kPa}\end{array}\right.$.

233 If there are reliable data available to make the calculation of $\kappa_{e}$ possible, the ending

234 compression index for $p^{\prime}>5,000 \mathrm{kPa}$, the line $\mathrm{OAB}$ can be more accurately described as 235 follows:

$236\left\{\begin{array}{c}I_{v}=2-0.4343 \ln p^{\prime} \text { for } p^{\prime} \leq 5000 \mathrm{kPa} \\ I_{v}=\kappa_{e} \ln \left(5000 / p^{\prime}\right)-1.699 \text { for } p^{\prime}>5000 \mathrm{kPa}\end{array}\right.$.

237 The only difference between Equation (10) and Equation (11) is in the magnitudes of the 238 compression index beyond $p^{\prime}=5000 \mathrm{kPa}$. If the compression index beyond $p^{\prime}=5000 \mathrm{kPa}$

239 could be identified reliably for a given soil and its value is found to be different from 0.1086 ,

240 equation (11) is recommended.

241 Model 1: If only $e^{*}{ }_{100}$ and $e^{*}{ }_{1000}$ for a given soil are known, measured or estimated via 242 equations (7) and (8), the intrinsic compression line for reconstituted clays OAB, i.e., 243 equation (10), is employed to represent the compression behaviour of the soil.

244 Model 2: Model 2 is applicable when an initial soil state $\left(e_{i}, p_{i}^{\prime}\right)$ is known in addition to the 245 values of $e^{*}{ }_{100}$ and $e^{*}{ }_{1000 .}$ A sketch of the model is shown in Fig. 3.

246 The position of the initial state, represented by $\left(e_{i}, p^{\prime}{ }_{i}\right)$, in relation to the intrinsic compression

247 line $\mathrm{OAB}$, is identified by the following set of equations

$248\left\{\begin{array}{l}2-0.4343 \ln p^{\prime}-I_{v, i}>0 \text { Initial state above ICL } \\ 2-0.4343 \ln p^{\prime}-I_{v, i}=0 \quad \text { Initial state on ICL } \\ 2-0.4343 \ln p^{\prime}-I_{v, i}<0 \text { Initial state below ICL }\end{array}\right.$

249 where $I_{v, i}$ is the void index for the initial state. 
250 The compression behaviour of the soil can be described by the set of constitutive equations, 251 depending on the position of the initial soil state (Fig. 3).

252 For a soil with an initial state on $\mathrm{ICL}^{*}$, the behaviour of the soil described by OAB or by

253 Model 1 is consistent with available data. Equation (10) or (11) gives a reliable description of 254 the soil behaviour.

255 If the initial state of a soil is below $\mathrm{ICL}^{*}$, the behaviour of the soil is described by $1 \mathrm{FAB}$ (Fig. 256 3). The gradient of line $1 \mathrm{~F}$, denoted by $\kappa_{i}$, is the initial compression index. $\mathrm{F}$ is the point 257 where the initial compression line and the intrinsic compression line intersect. $p_{F}^{\prime}$ is the mean 258 effective stress at that point. The behaviour of the soil represented by $1 F A B$ is described by 259 the following set of constitutive equations

$260\left\{\begin{array}{l}I_{v}=I_{v, i}-\kappa_{i} \ln \left(p^{\prime} / p_{i}^{\prime}\right) \quad \text { for } p^{\prime} \leq p_{F}^{\prime} \\ I_{v}=2-0.4343 \ln p^{\prime} \quad \text { for } p_{F}^{\prime}<p^{\prime} \leq 5000 \mathrm{kPa} \\ I_{v}=-0.775-0.1086 \ln p^{\prime} \quad \text { for } p^{\prime}>5000 \mathrm{kPa}\end{array}\right.$.

261 The mean effective stress at the intersection point $\mathrm{F}$ is expressed as follows:

$262 \quad p_{F}^{\prime}=\exp \left(\frac{2-I_{v, i}}{0.4343-\kappa_{i}}\right)$.

263 For situations in which the value of the parameter $\kappa_{i}$ is unknown, the following empirical 264 equation is proposed

$$
\kappa_{i}=0.0125\left(1+0.5 I_{v, i}{ }^{3}\right) \quad \text { for }-0.9 \leq I_{v, i} \leq 5 .
$$

266 It is obvious that $\kappa_{i}$ must always be greater than zero. Thus, based on experimental 267 observation a condition for applicability of the equation, $-0.9 \leq I_{v, i} \leq 5$, is imposed.

268 The proposed equation is based on analysis of a set of experimental data. A comparison of 269 the values of $\kappa_{i}$ between those measured and those predicted via equation (15) is shown in 
270 Fig 4. In the figure, data from fifty-six tests on eleven clays are shown. The experimental data

271 are reported by Terzaghi (1953), Cotecchia (1996), Wang and Wei (1996), Suzuki et al

272 (2007), Takemura et al, (2007), Hong et al (20110), Shipton and Coop, (2012). It should be

273 noted that the parameter $I_{v, i}$ is used in equation (15) for simplicity and is a pragmatic

274 approach. The methodology is similar to the usage of $p_{e}^{\prime}$, the equivalent confining stress

275 (Muir-Wood, 1990; Graham, 2006).

276 For a soil with an initial state above ICL $^{*}$ (Fig. 3), the behaviour of the soil is described by

$2772 \mathrm{CAB}$ for $p_{i}{ }_{i}<100 \mathrm{kPa}$ and $I_{v, i}>0$, or is described by $3 \mathrm{AB}$ for ${p^{\prime}}_{i} \geq 100 \mathrm{kPa}$ or $I_{v, i} \leq 0$.

278 For $p_{i}^{\prime}<100 \mathrm{kPa}$ and $I_{v, i}>0$, the gradient for line $2 \mathrm{C}$ is denoted by $\kappa_{2 C}$. The compression

279 behaviour of the soil, passing through point $\mathrm{C}(100 \mathrm{kPa}, 0)$, is described by the following set 280 of constitutive equations

$281\left\{\begin{array}{lc}I_{v}=I_{v, i}-\kappa_{2 C} \ln \left(p^{\prime} / p_{i}^{\prime}\right) & \text { for } p^{\prime} \leq 100 \mathrm{kPa} \\ I_{v}=2-0.4343 \ln p^{\prime} & \text { for } 100 \mathrm{kPa}<p^{\prime} \leq 5000 \mathrm{kPa} \\ I_{v}=-0.775-0.1086 \ln p^{\prime} & \text { for } p^{\prime}>5000 \mathrm{kPa}\end{array}\right.$.

282 Based on the values of the void index and mean effective stress for points 2 and $\mathrm{C}$, the 283 gradient $\kappa_{2 C}$ for line $2 \mathrm{C}$ is expressed as follows:

$284 \kappa_{2 C}=\frac{I_{v, 2}-I_{v, 100}}{\ln \left(100 / p_{2}^{\prime}\right)}=\frac{I_{v, 2}}{4.605-\ln p_{2}^{\prime}}$.

285 For $p_{i}^{\prime} \geq 100 \mathrm{kPa}$ or $I_{v, i} \leq 0$, the compression line cannot be assumed to pass through point $\mathrm{C}$,

286 because a negative compression index is indicated. Thus, the compression behaviour is 287 assumed to be $3 \mathrm{AB}$, and the gradient for line $3 \mathrm{~A}$ is denoted by $\kappa_{3 \mathrm{~A}}$. The compression 288 behaviour of the soil is described by the following set of constitutive equations 
$289\left\{\begin{array}{lr}I_{v}=I_{v, i}-\kappa_{3 A} \ln \left(p^{\prime} / p_{i}^{\prime}\right) & \text { for } p^{\prime} \leq 1000 \mathrm{kPa} \\ I_{v}=-0.775-0.1086 \ln p^{\prime} & \text { for } p^{\prime}>5000 \mathrm{kPa}\end{array}\right.$.

290 Based on the values of the void index and mean effective stress for points 3 and A, the

291 gradient $\kappa_{2 C}$ for line $3 \mathrm{~A}$ is expressed as follows:

$292 \kappa_{3 A}=\frac{I_{v, 3}-I_{v, 1000}}{\ln \left(1000 / p_{3}^{\prime}\right)}=\frac{I_{v, 3}}{6.908-\ln p_{3}^{\prime}}$.

293 Model 3: Model 3 is applicable in situations in which all three sets of data are available,

$294 e^{*}{ }_{100}$ and $e^{*}{ }_{1000}$, an initial soil state $\left(e^{*}, p^{\prime}{ }_{i}\right)$, and the yielding stress $p^{\prime}{ }_{y}$. Model 3 is an 295 improvement over Model 2 in that it incorporates the influence of the yield stress on soil 296 behaviour. Consequently, there is a change in the soil compression index around the yielding 297 point, indicated as point $\mathrm{Y}$ in Fig. 5. The initial behaviour of the soil from $p_{i}^{\prime}$ and $p^{\prime}{ }_{y}$ is 298 described by the initial behaviour either with the initial compression index, if the soil 299 experiences virgin yielding, or the unloading and reloading compression index, if the soil 300 experiences subsequent loading. Beyond the yielding point $p_{y}^{\prime}$, the soil behaviour is 301 essentially the same as that described by Model 2. As shown in Fig 5, the soil behaviour is 302 represented by the following four linear segments 4 YCAB if the position of the yielding point $303 p_{y}^{\prime}$ is above $\mathrm{ICL}^{*}$, with $p^{\prime}{ }_{y}<100 \mathrm{kPa}$ and $I_{v, i}>0$. The gradient for line $\mathrm{YC}$ is denoted by $\kappa_{Y C}$.

$\left\{\begin{array}{lc}I_{v}=I_{v, i}-\kappa_{i} \ln \left(p^{\prime} / p_{i}^{\prime}\right) & \text { for } p^{\prime} \leq p_{y}^{\prime} \mathrm{kPa} \\ I_{v}=I_{v, y}-\kappa_{Y C} \ln \left(p^{\prime} / p_{y}^{\prime}\right) & \text { for } p_{y}^{\prime}<p^{\prime} \leq 100 \mathrm{kPa} \\ I_{v}=2-0.4343 \ln p^{\prime} & \text { for } 100 \mathrm{kPa}<p^{\prime} \leq 5000 \mathrm{kPa} \\ I_{v}=-0.775-0.1086 \ln p^{\prime} & \text { for } p^{\prime}>5000 \mathrm{kPa}\end{array}\right.$.

305 As a result, the value of the void index at the yield point $\mathrm{Y}$ can be determined by substituting

306 the value of the stress at that point into the equation for line $4 \mathrm{Y}$, and its value is given as 307 follows: 
309 where $I_{v, i}$ is the void index at the initial point 4 , and $\kappa_{i}$ is the initial compression index.

310 Based on the values of the void index and the mean effective stress for points $\mathrm{Y}$ and $\mathrm{C}$, the

311 gradient $\kappa_{Y C}$ for line $\mathrm{YC}$ is determined as follows:

$312 \kappa_{Y C}=\frac{I_{v, Y}-I_{v, 100}}{\ln \left(100 / p_{y}^{\prime}\right)}=\frac{I_{v, Y}}{4.605-\ln p_{y}^{\prime}}$.

\section{$313 \quad 2.4$ Discussion of the application of the proposed tool}

\section{2.4.1. $\boldsymbol{p}^{\prime}{ }_{y}$ : the yielding mean effective stress or the maximum historical stress}

315 As noted in Section 2.2, the general shape of the compression curve in the $e \sim \ln p^{\prime}$ space or

316 the $I_{v} \sim \ln p^{\prime}$ space is not a straight line, but rather an S-shape (Liu et al, 2013). If the actual

317 compression curve is represented by a number of segmented lines, there will be a number of

318 points at which the value of the compression index changes sharply, which falls into the

319 definition of traditional yielding stress (e.g., Coop and Atkinson, 1993; Khalili et al, 2005;

320 Airey et al, 2011). In this study, the term yielding is used to indicate a sharp change in the

321 slope of the soil compression curve, irrespective of whether the change is due to the nature of

322 the compression or by unloading or reloading. The difference in initial compression or

323 unloading and reloading is normally modelled via the compression index.

\section{$324 \quad$ 2.4.2. Parameters for void ratio and for void index}

325 The relationship between the void ratio and the void index is expressed by equation (3). A

326 basic parameter in engineering computation and theoretical constitutive modelling is the

327 constant compression index in the $e \sim \ln p^{\prime}$ space. The index in the $e \sim \ln p^{\prime}$ space, $K_{e}$, and that

328 in the $I_{v} \sim \ln p^{\prime}$ space, $\kappa_{I v}$, are related by the following equation. 
$329 K_{e}=\kappa_{I V} C_{c}^{*}$

330 In this study, linear segmental compression behaviour for clays is suggested. Therefore, the

331 compression index is dependent on the stress level. The corresponding index for the intrinsic

332 compression line $\mathrm{OAB}$ is as follows:

$333\left\{\begin{array}{l}K_{e}=0.4343 C_{c}^{*} \text { for } p^{\prime} \leq 5000 \mathrm{kPa} \\ K_{e}=0.1086 C_{c}^{*} \text { for } p^{\prime}>5000 \mathrm{kPa}\end{array}\right.$.

334 For a soil with an initial compression index calculated via equation (15), the index for

335 deformation measured by the void ratio is given by the following equation:

$336 K_{e, i}=0.0125\left(1+0.5 I_{I, i}^{3}\right) C_{c}^{*}$.

\section{2.4.3. Methods in the $I_{v} \sim \ln \sigma^{\prime}{ }_{v}$ space}

338 As stated in Section 2.2, the compression behaviour of soil normalised by $I_{v}$ is graphically

339 identical in the $I_{v} \sim \ln p^{\prime}$ space and in the $I_{v} \sim \ln \sigma^{\prime}{ }_{v}$ space. In geotechnical engineering, it is a

340 common practice to substitute the vertical effective stress $\sigma^{\prime}{ }_{v}$ for the mean effective stress $p^{\prime}$

341 when describing one-dimensional compression behaviour (e.g., Burland 1990; Liu et al,

342 2003; Chai and Carter, 2011). Consequently, the proposed models and the constitutive

343 equations remain essentially the same when the mean effective stress $p^{\prime}$ is replaced by the

344 vertical effective stress $\sigma^{\prime}{ }_{v}$. For example, the intrinsic compression line OAB in the $I_{v} \sim \ln \sigma^{\prime}{ }_{v}$

345 space is described by the following equation:

$346\left\{\begin{array}{lr}I_{v}=2-0.4343 \ln \sigma_{v}^{\prime} & \text { for } \sigma_{v}^{\prime} \leq 5000 \mathrm{kPa} \\ I_{v}=-0.775-0.1086 \ln \sigma_{v}^{\prime} & \text { for } \sigma_{v}^{\prime}>5000 \mathrm{kPa}\end{array}\right.$.

347 Parameter $C_{c, v} *$ is expressed as follows:

$348 C_{c, v}{ }^{*}=e_{100, v}^{*}-e_{1000, v}^{*}$. 
349 Consequently, the void ratio and the void index are related by the following equation:

$350 \quad e_{v}^{*}=I_{v} C_{c, v}^{*}+e_{100, v}^{*}$

351 and the compression index in the $e \sim \ln \sigma^{\prime}{ }_{v}$ space, $K_{e, v}$, and that in the $I_{v} \sim \ln p^{\prime}$ space, $\kappa_{I V}$, are

352 related by the following equation.

$353 K_{e, v}=K_{I v} C_{c, v}{ }^{*}$

354 It should be noted that the compression index in the $e \sim \ln \sigma^{\prime}{ }_{v}$ space is identical to that in the $355 e \sim \ln p^{\prime}$ space.

\section{3. Validation of Proposed Models}

\section{$357 \quad 3.1 \quad$ Background}

358 The proposed systematic tool has been applied to analysis of the behaviour of many different

359 types of reconstituted clays. The simulations for six types of reconstituted clays, with 10 tests

360 in total, are presented here. Details of tests can be found in the original reports and their

361 references are listed in Table 2. The values of the soil parameters used in the theoretical

362 simulations are also given in Table 2. Simulations are conducted for all three models.

363 Comparisons between the experimental data and the theoretical simulation results are shown

364 in Figs 6 to 15. Of the six groups of test results considered here, the mean effective stresses

365 are reported for one group, Bisaccia clay. The results are shown in Fig. 13. The rest of the

366 tests are one-dimensional compression tests and only the values of the vertical effective stress

367 are reported.

368 The stress units adopted here are kilopascals $(\mathrm{kPa})$. The proposed empirical equation for the 369 initial compression index, i.e., equation (15), is employed for the simulations presented in this 370 study. Because the void ratio is used directly in engineering computations, all the simulations 
are presented in the $e-\ln p^{\prime}$ space. The values of the initial yield stress have been identified

372 directly from the original compression curves plotted in terms of $e-\ln p^{\prime}$ or $I_{v}-\ln p^{\prime}$ co-

373 ordinates.

374 The experimental data are represented by solid symbols, such as circles or squares. The

375 simulation results obtained via Model 1 are represented by dark solid lines, those obtained via

376 Model 2 are represented by broken lines of dark dots, and those obtained via Model 3 are

377 represented by dark broken lines without dots. It should be noted that the simulation results

378 for Models 2 and 3 will usually be coincident with those for Model 1 for further loading after

379 the compression curve meets OAB. As a result, only dark lines are shown in the figures after

380 the other two models merge into Model 1. When the simulation results obtained using Model

3811 and those obtained using Model 2 or Model 3 are identical, the simulation results are

382 represented by one curve, the dark solid lines as indicated in the legends. Similarly, the

383 simulation results are represented dark broken lines without dots when the simulation results

384 obtained using Model 2 and those obtained using Model 3 are identical.

\section{$385 \quad 3.2$ Evaluation and discussion}

386 An overall view of the compression behaviour of various reconstituted clays is shown in Fig.

387 2. The test results selected for the simulation presentation are marked by solid symbols linked

388 with thin lines, and the other tests are by marked by open symbols linked with thin lines. Soft

389 Louisville clay and kaolin clay with initial void ratios of approximately 0.7 form the upper

390 and lower bands of the collection and are selected for simulation. The stress levels for all the

391 simulations vary from $0.1 \mathrm{kPa}$ to $20,000 \mathrm{kPa}$. The stress ratio levels reach as high as 5,000 for

392 soft Louisville clay and 8,000 for Lianyugang clay. The void index varies from -1.8 to 7.6.

393 The void ratio varies from 0.3 to 24 . All tests forming the bands of the ranges are selected for

394 the simulations. The tests selected for the simulations are a reasonably good representation of 
all the data collected.

396 Model 1 yields a good prediction of reconstituted clay behaviour in the range of $100 \mathrm{kPa}$ to $3971,000 \mathrm{kPa}$. Outside that range, Model 1 should only be used as a rough estimation. For some 398 clays, considerable disagreement is expected between Model 1 , or the proposed $\mathrm{I}_{\mathrm{V}} \mathrm{CL}^{*}$, and 399 the actual soil behaviour. Generally speaking, the prediction via Model 1 is more reliable for 400 stresses greater than $1,000 \mathrm{kPa}$ than for stresses less than $100 \mathrm{kPa}$. A conclusion can be drawn 401 that the intrinsic compression curves of reconstituted clays are dependent on the types of the clays and their initial water contents, especially for $p^{\prime}<100 \mathrm{kPa}$.

In general, Model 2 provides a reasonably good estimation of the compression behaviour of 404 clays over a very wide range of stresses and water contents. An additional information such 405 as the initial stress and the void ratio state, can be implemented conveniently into the 406 proposed model and will result in significant improvement in the engineering computations.

407 Because the yielding stress of the soil is known and implemented into Model 3, Model 3 408 yields an overall satisfactory description of the compression behaviour of reconstituted clays, 409 and this model can be used reliably in engineering computations of soil void ratios and 410 compression index values. Fig. 10 shows that for soft Louisville clay, a considerable 411 difference between the simulation results and the experimental data exists. A major factor in 412 this difference is that the value of the initial compression index, determined via the empirical 413 equation (15), is not accurate. Consequently, the compression of soil is seriously over 414 predicted from the initial state to the yielding point. Another special point about this 415 simulation is that the stress starts at a very low level, $0.1 \mathrm{kPa}$. For comparison, the simulation 416 with an accurate value of the index is also shown in Fig. 10. Because Model 3 allows the 417 usage of an accurate initial compression index in the simulation (as described in equation 11), 418 the model is able to represent the behaviour of reconstituted clays well. 
419 The simulation results in Fig. 6 to Fig. 15 show that the $\mathrm{I}_{\mathrm{v}} \mathrm{CL}^{*}$, or $\mathrm{OAB}$, is the basis of all 420 three models. The predictions made by using Model 2 and Model 3 eventually agree and 421 coincide with the $\mathrm{I}_{\mathrm{v}} \mathrm{CL}^{*}$. For five cases, the simulation results obtained via Model 2 and those 422 obtained via Model 3 are identical. For two cases (Figs 12 and 13), there is no obvious 423 yielding point and thus there is no difference between Model 2 and Model 3. For the other 424 three cases (Figs 9, 11 and 14), the yielding state occurs in the vicinity of the $\mathrm{I}_{\mathrm{v}} \mathrm{CL}^{*}$. Under 425 these conditions, Model 2 and Model 3 predict the same turning point for the compression 426 behaviour.

427 The proposed empirical equation for the initial compression index, i.e., Equation (15), is 428 employed to simulate the initial behaviour of four clays in eight tests. For soft Louisville clay 429 (Fig. 10), the initial void index is too high $\left(I_{v, i}=7.6\right)$ and the empirical equation for $k_{i}$ is not 430 applicable. Overall speaking, the simulations made via the proposed empirical equation 431 provide acceptable estimates of the soil's initial behaviour when it diverges from the unique $432 \mathrm{I}_{\mathrm{v}} \mathrm{CL}^{*}$. The maximum value of compression index of a clay usually occurs in the stress range 433 from $100 \mathrm{kPa}$ to $1,000 \mathrm{kPa}$; however, for clays with very high initial $I_{v}$, the initial 434 compression index can be greater than the value that occurs in the range of $100 \mathrm{kPa}$ to 1,000 435 kPa (e.g.; Burland et al, 1996; Liu et al, 2003; Khalili et al, 2005).

436 As shown Fig. 13 for Bisaccia clay, the unloading and reloading behaviour of reconstituted 437 clay is simulated simply by following the same conventional compression model as that used 438 for Cam Clay, which is assumed to behave linear elastically in the $e-\ln p^{\prime}$ space in both 439 unloading and reloading. The concepts and methods for describing conventional elastic 440 behaviour can be incorporated straightforward into the proposed method.

441 Index properties of clayey soils are directly dependent on the mineralogy of the soils. Many 442 studies have been reported on the correlations of the compressibility of clayey soils and index 
properties (e.g., Skempton, 1944; Bowles, 1989; Muir Wood, 1990; Burland, 1990; Sridharan

444 and Nagaraji, 2000; Horpibulsuk et al, 2013). Based on these studies, the virgin compression

445 index of a clay can usually be estimated from the liquid limit or the initial void ratio of the

446 soil. The proposed equation (15), though based on the void index concept, is in consistency

447 with these works. It is seen that the proposed equation provides a reasonably good agreement

448 with experimental data. Hence it seems possible that for the purpose of primary estimation

449 the proposed models can be further developed with all model parameters estimated via index

450 properties. It may also be possible to normalize the index properties by parameters such as

$451 e_{v, 100}^{*}$, and $e_{v, 1000}^{*}$. Thus, the general feature of the compression behavior of reconstituted

452 clays, i.e., a unique curve in the $I_{v}-\ln p^{\prime}$ space for $p^{\prime} \geq 100 \mathrm{kPa}$, can be described. This will

453 be a future study topic.

454 It should also be noted that the compression of clays even in the simplest states, reconstituted

455 states, is very complicated. The proposed tool, which is based on limited experimental data

456 may not be applicable to some clays. A study of the compression behaviour of reconstituted 457 soils in terms of influential factors such as the clay minerals and the double layer 458 characteristics may provide insight into the mechanisms and parameters of compression 459 behaviour. This may be a topic of further research.

\section{4. Conclusions}

461 A simple systematic tool based on Burland's void index is proposed for use in estimating the 462 compression behaviour of reconstituted clays. The compression behaviour of clays is 463 idealised as linear segments in the $I_{v} \sim \ln p^{\prime}$ space. Based on available data, three related but 464 independent models are proposed for use in predicting the compression behaviour of clays, 465 which is a key soil characteristic in engineering computation and constitutive modelling. The 
proposed estimation is employed to simulate the behaviour of various reconstituted clays and the simulations are compared with experimental data. The proposed estimations make maximum use of the available data, and the accuracy of the estimation increases with the level of the available data. The proposed estimation is a simple yet practical tool for calculating the compression behaviour of reconstituted clays and the soil compression index and is suitable for use in describing clay compression behaviour over a wide range of stresses, i.e., $1 \mathrm{kPa}<p^{\prime}<100,000 \mathrm{kPa}$, and a wide range of water contents. An empirical equation for the initial compression index is also suggested. This equation has been found to be very useful in predicting the initial compression behaviour of clays, which is usually expected to diverge from the standard intrinsic compression line, $\mathrm{I}_{\mathrm{v}} \mathrm{CL}^{*}$.

\section{References}

Adachi, T, Oka, F, Hirata, T, Hashimoto, T, Nagaya J, Mimura, M and Pradhan, TBS 1995,

Airey, DW, Carter JP and Liu MD 2011, 'Sydney Soil model: (II) experimental evaluation', International J. of Geomechanics, ASCE, vol.11(3), pp.225-238.

Altuhafi, F, Baudet, BA and Sammonds P 2011, 'On the particle size distribution of a basaltic till', Géotechnique, vol.51(1), pp.113-121.

Amorosi, A and Rampello, S 2007, 'An experimental investigation into the mechanical behaviour of a structured stiff clay', Géotechnique, vol.57, pp.153-166.

Baudet, BA and Stallebrass, SE 2001, 'Modelling the destructuring of soft natural clays', Computer Methods and Advances in Geomechanics, vol.1, pp.297-302.

Bobet, A, Hwang, J, Johnston, CT and Santagata, M 2011, 'One-dimensional consolidation behavior of cement-treated organic soil', Canadian Geotechnical Journal, Vol.48(7), pp.1100-1115.

491 Bowles, JE 1989, Physical and Geotechnical Properties of Soils, McGraw-Hill, New York.

492 Burland JB 1990, 'On the compressibility and shear strength of natural soils', Géotechnique, 493 vol.40, pp.329-378. 
Burland, JB, Rampello, S, Georgiannou, VN and Calabresi, G 1996, 'A laboratory study of the strength of four stiff clays', Géotechnique, vol.46, pp.491-514.

Chai, JC, Miura, N, and Zhu, HH 2004, 'Compression and consolidation characteristics of structured natural clays', Canadian Geotechnical Journal, vol.41, no.6, pp.1250-1258.

Chai, J and Carter, JP 2011, 'Deformation Analysis in Soft Ground Improvement'. Springer, $499 \quad$ New York.

500 Coop, MR and Atkinson, JH 1993, 'The mechanics of cemented carbonate sands', 501 Géotechnique, vol. 43(1), pp.53-67.

502 Cotecchia, F 1996, 'The effect of structure on the properties of an Italian pleistocene clay', $503 \quad \mathrm{PhD}$ thesis, University of London, London

Desai, CS and Toth, J 1996, 'Disturbed state constitutive modelling based on stress-strain and 505 non-destructive behaviour', Int. J. of Solids and Structures, vol.33, pp.1619-1650.

Fukue, M and Mulligan, CN 2009, 'Equations of state in soil compression based on statistical mechanics', Soils and Foundations, vol.49(1), pp.99-114.

Gasparre, A and Coop, MR 2008, 'Quantification of the effects of structure on the compression of a stiff clay', Canadian Geotechnical Journal. Vol.45(9), pp.1324-1334.

Graham, J 2006, 'The 2003 R.M. Hardy Lecture: soil parameters for numerical analysis in clay', Canadian Geotechnical Journal, vol.43(2), pp.187-209.

Hanzawa, H and Adachi, K 1983, 'Overconsolidation of alluvial clays', Soils and Foundations, vol.23(4), pp.106-118.

514 Hinchberger, SD and Qu, G 2009, 'Viscoplastic constitutive approach for rate-sensitive structured clays', Canadian Geotechnical Journal, vol.46(6), pp.609-626.

Hong, Z, Yin, J and Cui, YJ 2010, 'Compression behavior of reconstituted soils at high initial

water contents', Géotechnique, vol.60(9), pp.691-700.

518 Hong, Z and Onitsuka, K 1998, 'A method of correcting yield stress and compression index 519 of Ariake clays for sample disturbance', Soils and Foundations, vol.38(2), pp.211-222.

520 Horpibulsuk, S, Shibuya, S, Fuenkajorn, K and Katkan, W 2007, 'Assessment of engineering 521 properties of Bangkok clay’, Canadian Geotechnical Journal, vol.44(2), pp.173-187.

522 Horpibulsuk, S, Liu MD, Liyanapathirana, S and Suebsuk, J 2010, 'Behaviour of cemented 523 clay simulated via the theoretical framework of the SCC model', Computers and 524 Geotechnics, vol.37(1), pp.1-9. 
525

526

527

528

529

530

531

532

533

534

535

536

537

538

539

540

541

542

543

544

545

546

547

548

549

550

551

552

553

554

555

556

Horpibulsuk, S, Yangsukaseam, N, Chinkulkijniwat, A, and Du, YJ 2011, 'Compressibility and permeability of Bangkok clay compared with kaolinite and bentonite', Applied Clay Science, Vol.52, pp.150-159.

Horpibulsuk, S, Rachan, R, Suddeepong, A, Liu, MD and Du, YJ 2013, 'Compressibility of lightweight cemented clays', Engineering Geology, Vol.159, pp.59-66.

Khalili, N, Habte, MA and Valliappan, S 2005, 'A bounding surface plasticity model for cyclic loading of granular soils', International J. for Numerical and Analytical Methods in Geomechanics, vol.63, pp.1939-1960.

Lancellotta, R and Pepe, C 1990, "Mechanical behaviour of upper Pisa clay", Internal report, Technical University of Torino.

Lehane, B and Faulkner, A 1998, 'Stiffness and strength characteristics of a hard lodgement till, Proc. IV Eur. Conf. on the Geotechnics of Hard Soils and Soft rocks, Naples, vol.2, pp.637-646.

Leonard, GA 1972, Discussion of "Shallow foundation", Proceedings of ASCE Spec. Conf. on Perf. of Earth and Earth supported Struct., ASCE, New York, vol.3, pp.169-173.

Leroueil, S and Vaughan, PR 1990, 'The general and congruent effects of structure in natural soils and week rock', Geotechique, 40, pp.467-488.

Leroueil, S, Tavenas, F, Brucy, F, La Rochelle, P, and Roy, M 1979, 'Behavior of destructured natural clays'. Journal of Geotechnical Engineering, ASCE, vol.105(6), pp.759-778.

Leroueil, S, Tavenas, F, Samson, L, and Morin, P 1983, 'Preconsolidation pressure of Champlain clay. Part II: Laboratory determination', Canadian Geotechnical Journal, vol.20(4), pp.803-816.

Liu MD and Carter JP 1999, 'Virgin compression of structured soils', Géotechnique, vol.49(1), pp.43-57.

Liu, MD, Carter, JP, Desai, CS and Xu, KJ 2000, 'Analysis of the compression of structured soils using the disturbed state concept', Int. J. for Numerical and Analytical Methods in Geomechanics, vol.24, pp.723-735.

Liu, MD and Carter, JP 2000, 'On the volumetric deformation of reconstituted soils', Int. J. for Numerical and Analytical Methods in Geomechanics, vol.24(2), pp.101-133.

Liu, MD and Carter, JP 2002, 'Structured Cam Clay Model', Canadian Geotechnical Journal, vol. 39(6), pp.1313-1332. 
557

558

559

560

561

562

563

564

565

566

567

568

569

570

571

572

573

574

575

576

577

578

579

580

581

582

583

584

585

586

587

588

Liu, MD, Carter, JP, Desai, CS 2003, 'Modelling the compression behaviour of geomaterials', International J. of Geomechanics, ASCE, vol. 3(3/4), pp.191-204.

Liu, MD, Carter, JP and Airey, DW 2011, 'Sydney Soil model: (I) theoretical formulation', International J. of Geomechanics, ASCE, vol.11(3), pp.211-224.

Liu, MD, Xu, K, and Horpibulsuk, S 2013, 'A mathematical function for the S-shaped relationship', Proceedings of the ICE - Geotechnical Engineering, vol.166(3), pp.321-327.

Locat, J and Lefebvre, G 1985, 'The compressibility and sensitivity of an artificially sedimented clay soil: the Grande-Baleine marine clay, Quebec', Marine Geotechnology, vol.6(1), pp.1-27.

Locat, L, Tremblay, H and Leroueil, S 1996, 'Mechanical and hydraulic behaviour of a soft inorganic clay treated with lime', Canadian Geotechnical Journal, vol.33, pp.654-669.

Low, H, Phoon, K, Tan, T, and Leroueil, S 2008, 'Effect of soil microstructure on the compressibility of natural Singapore marine clay', Canadian Geotechnical Journal, vol.45(2), pp.162-176.

Masín, D 2007, 'A hypoplastic constitutive model for clays with meta-stable structure', Canadian geotechnical journal, vol.44(3), pp.363-375.

Michell, JK 1986, 'Practical problems from surprising soil behavior', Journal of Geotechnical Engineering, ASCE, vol.112(3), pp.259-289.

Mitchell, JK 1996, Fundamentals of soil behavior, John Willey\&Sons Inc., New York, 437p.

Muir-Wood, D 1990, Soil Behaviour and Critical State Soil Mechanics, Cambridge University Press.

Mesri, G Rokhsar, A and Bohor, BF 1975, 'Composition and compressibility of typical samples of Mexico City clay', Canadian Geotechnical Journal. vol.25(3), pp.527-554.

Nagaraj, TS and Miura, N 2001, Soft Clay Behaviour: Analysis and Assessment. Rotterdam. Balkema, 315p.

Nagaraj, TS, Srinivasa Murthy, BR, Vatsala, A and Joshi, RC 1990, 'Analysis of compressibility of sensitive clays', Journal of Geotechnical Engineering, ASCE, vol.116(GT1), pp.105-118.

Nagaraj, TS, Pandian, NS, and Narasimha Raju, PSR 1998, 'Compressibility behavior of soft cemented soils', Geotechnique, vol.48(2), pp.281-287.

Nova, R and Wood, DM 1979, 'A constitutive model for sand in triaxial compression', Int. J. Numerical Analytical Method in Geomechanics, vol.3, pp.255-278. 
589 Pestana, JM and Whittle, AJ 1995, 'Compression model for cohesionless soils', 590 Géotechnique, vol.45, pp.621-631.

Potts, DM and Zdravkovic, L 1999, Finite Element Analysis in Geotechnical Engineering: Theory, Thomas Telford, London.

Onofrio, A, Magistris, FS 1998, 'Influence of soil structure on the behaviour of two natural stiff clays in the pre-failure range', The Geotechnics of Hard Soils-Soft Rocks, Balkema, Rotterdam, Italy.

Schmertmann, JH 1991, 'The mechanical aging of soils', Journal of Geotechnical Engineering, ASCE, vol.119(9), pp.1288-1330.

Schofield, AN and Wroth, CP 1968, Critical State Soil Mechanics, McGraw-Hill, London.

Shibuya, S 2000, 'Assessing structure of aged natural sedimentary clays', Soils and Foundations, vol.40(3), pp.1-16.

Skempton, AW 1944, 'Notes on compressibility of clays', Qaurterly Journal of the Geological Society, London, vol. 100(2), pp.119-135.

Shipton, B and Coop, MR 2012, 'On the compression behavior of reconstituted soils', Soils and Foundations, vol.52(4), pp.668-681.

Sridharan, A and Nagaraji, HB 2000, 'Compressibility behavior of remoulded, fine-grained soils and correlation with index properties', Canadian Geotechnical Journal, Vol. 37, pp.712-722.

Suebsuk, J, Horpibulsuk, S, and Liu, MD 2010, 'Modified Structured Cam Clay: A constitutive model for destructured, naturally structured and artificially structured clays',

611 Suebsuk, J, Horpibulsuk, S and Liu, MD 2011, 'A critical state model for overconsolidated 612 structured clays', Computers and Geotechnics, vol.38, pp.648-658.

613 Suzuki, M, Tsuzuki, S and Yamamoto, T 2007, 'Residual strength characteristics of naturally 614 and artificially cemented clay in reversal direct box shear test', Soils and Foundations, 615 vol.47(6), pp.1029-1044.

616 Takemura, J, Watabe, $\mathrm{Y}$ and Tanaka, M 2007, 'Characterization of alluvial deposits in 617 Mekong Delta', Characterization and Engineering Properties of Natural Soils, Taylor and 618 Francis group, London.

619 Terzaghi, K 1953, 'Fifty years of subsoil exploration', Proc.3rd Int. Conf. Soil Mech. Found. 620 Engng, Zurich, vol.1, pp.227-238. 
621 Wang, N and Wei, R1996, 'Evaluation of sample quality of soft clay', Proc. ${ }^{\text {nd }}$ Int. Conf. So 622 of soft clay. Proc. 2nd Int. Conf. Soft Soil Engng, pp.120-125, Nanjing, China. 
Table 1: Basic Data on Compression Tests of Reconstituted Soil from Previous Studies

\begin{tabular}{|c|c|c|c|c|c|c|}
\hline Soils & Reference & $\begin{array}{l}\text { Known } \\
\text { stresses }\end{array}$ & $\begin{array}{c}\text { No. of } \\
\text { tests }\end{array}$ & $\mathrm{e}^{*}{ }_{100}$ & $\mathrm{e}^{*} 1000$ & $\begin{array}{c}\text { Range of } \\
\text { stresses } \\
\text { (kPa) }\end{array}$ \\
\hline Osaka clay & Adachi et al, 1995 & $\sigma_{v}^{\prime}$ & 1 & 1.26 & 0.61 & $5-1000$ \\
\hline \multirow{14}{*}{ Baimahu Clay } & \multirow{14}{*}{ Hong et al, 2000} & \multirow{14}{*}{$\begin{array}{c}\sigma_{v}^{\prime} \\
14-\text { Tests }\end{array}$} & $\omega=64 \%$ & 1.23 & 0.75 & $0.5-1600$ \\
\hline & & & $\omega=72 \%$ & 1.25 & 0.71 & $0.5-1600$ \\
\hline & & & $\omega=83 \%$ & 1.33 & 0.68 & $0.5-1600$ \\
\hline & & & $\omega=91 \%$ & 1.33 & 0.73 & $0.5-1600$ \\
\hline & & & $\omega=101 \%$ & 1.39 & 0.77 & $0.5-1600$ \\
\hline & & & $\omega=111 \%$ & 1.50 & 0.80 & $0.5-1600$ \\
\hline & & & $\omega=119 \%$ & 1.45 & 0.82 & $0.5-1600$ \\
\hline & & & $\omega=126 \%$ & 1.52 & 0.81 & $0.5-1600$ \\
\hline & & & $\omega=137 \%$ & 1.54 & 0.78 & $0.5-1600$ \\
\hline & & & $\omega=143 \%$ & 1.58 & 0.86 & $0.5-1600$ \\
\hline & & & $\omega=153 \%$ & 1.62 & 0.86 & $0.5-1600$ \\
\hline & & & $\omega=163 \%$ & 1.68 & 0.90 & $0.5-1600$ \\
\hline & & & $\omega=174 \%$ & 1.70 & 0.92 & $0.5-1600$ \\
\hline & & & $\omega=180 \%$ & 1.72 & 0.95 & $0.5-1600$ \\
\hline \multirow{14}{*}{ Lianyugang Clay } & \multirow{14}{*}{ Hong et al, 2000} & \multirow{14}{*}{$\begin{array}{c}\sigma_{v}^{\prime} \\
14-\text { Tests }\end{array}$} & $\omega=50 \%$ & 0.99 & 0.62 & $0.5-1600$ \\
\hline & & & $\omega=59 \%$ & 1.05 & 0.68 & $0.5-1600$ \\
\hline & & & $\omega=68 \%$ & 1.13 & 0.73 & $0.5-1600$ \\
\hline & & & $\omega=78 \%$ & 1.26 & 0.78 & $0.5-1600$ \\
\hline & & & $\omega=85 \%$ & 1.28 & 0.74 & $0.5-1600$ \\
\hline & & & $\omega=92 \%$ & 1.28 & 0.73 & $0.5-1600$ \\
\hline & & & $\omega=96 \%$ & 1.35 & 0.74 & $0.5-1600$ \\
\hline & & & $\omega=104 \%$ & 1.37 & 0.81 & $0.5-1600$ \\
\hline & & & $\omega=114 \%$ & 1.34 & 0.77 & $0.5-1600$ \\
\hline & & & $\omega=119 \%$ & 1.36 & 0.79 & $0.5-1600$ \\
\hline & & & $\omega=127 \%$ & 1.43 & 0.79 & $0.5-1600$ \\
\hline & & & $\omega=135 \%$ & 1.45 & 0.81 & $0.5-1600$ \\
\hline & & & $\omega=142 \%$ & 1.51 & 0.83 & $0.5-1600$ \\
\hline & & & $\omega=146 \%$ & 1.54 & 0.83 & $0.5-1600$ \\
\hline \multirow{8}{*}{ Keman } & \multirow{8}{*}{ Hong et al, 2000} & \multirow{8}{*}{$\begin{array}{c}\sigma^{\prime}{ }_{v} \\
14-\text { Tests }\end{array}$} & $\omega=43 \%$ & 0.91 & 0.62 & $0.5-1000$ \\
\hline & & & $\omega=48 \%$ & 0.95 & 0.64 & $0.5-1000$ \\
\hline & & & $\omega=57 \%$ & 0.95 & 0.65 & $0.5-1000$ \\
\hline & & & $\omega=62 \%$ & 0.98 & 0.65 & $0.5-1000$ \\
\hline & & & $\omega=66 \%$ & 1.04 & 0.67 & $0.5-1000$ \\
\hline & & & $\omega=72 \%$ & 1.04 & 0.70 & $0.5-1000$ \\
\hline & & & $\omega=80 \%$ & 1.11 & 0.66 & $0.5-1000$ \\
\hline & & & $\omega=87 \%$ & 1.17 & 0.71 & $0.5-1000$ \\
\hline
\end{tabular}




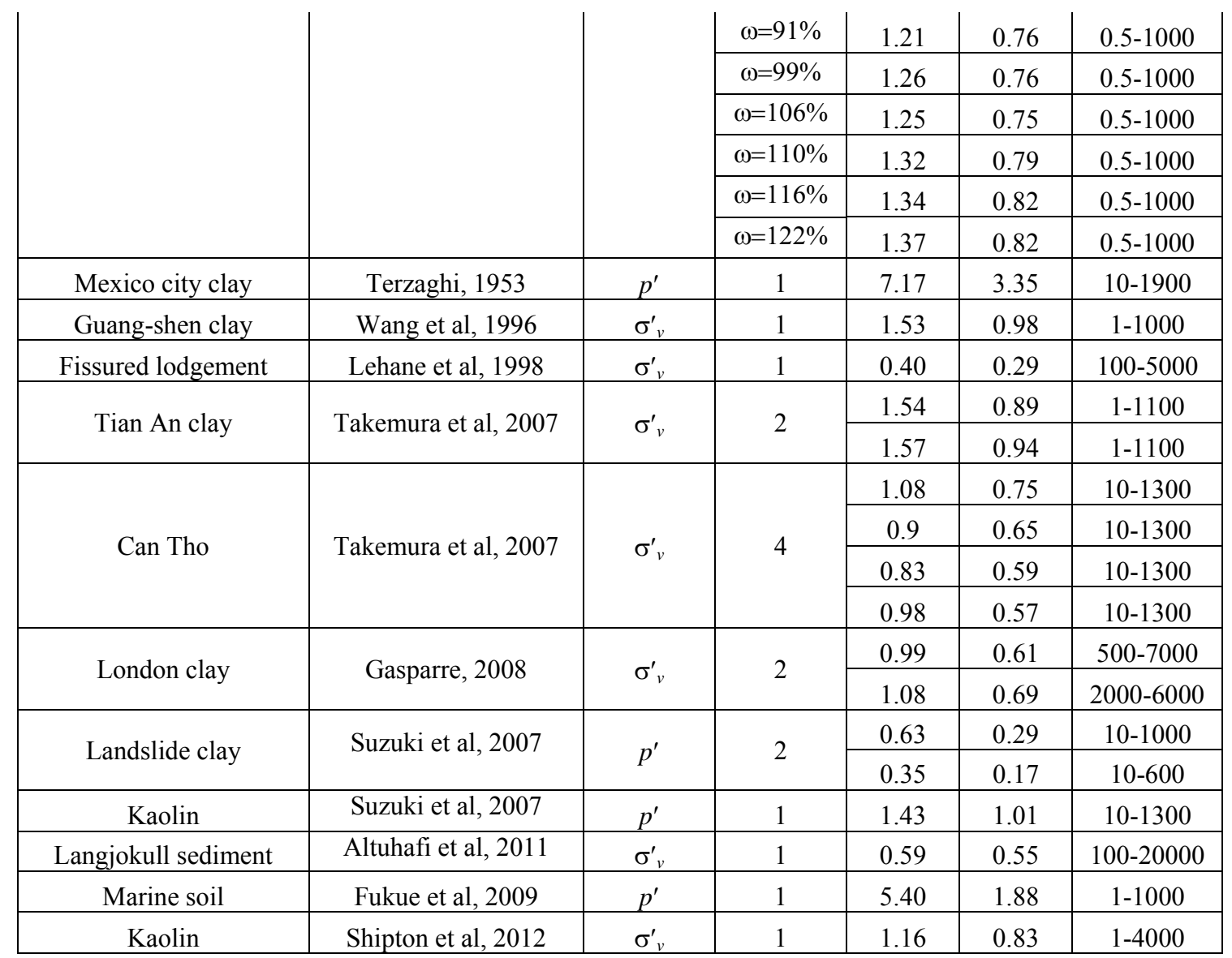

625

626

627

628 
Table 2: Compression Test Results for the Validation of Proposed Models of prediction for Compression Index

\begin{tabular}{|c|c|c|c|c|c|c|c|c|c|c|}
\hline \multirow{2}{*}{ Soils } & \multirow{2}{*}{ Reference } & \multirow{2}{*}{$\begin{array}{l}\text { Stress } \\
\text { known }\end{array}$} & \multirow{2}{*}{$\begin{array}{c}\text { No. of } \\
\text { tests }\end{array}$} & \multirow{2}{*}{$e^{*} 100$} & \multirow{2}{*}{$e^{*} 1000$} & \multicolumn{2}{|c|}{ Initial soil state } & \multirow{2}{*}{$\begin{array}{c}\text { Yield } \\
\text { stress } \\
\text { (kPa) }\end{array}$} & \multirow{2}{*}{$\begin{array}{l}\text { Stress } \\
\text { range } \\
(\mathbf{k P a})\end{array}$} & \multirow{2}{*}{ Simulations } \\
\hline & & & & & & $e^{*}{ }_{i}$ & $p_{i}^{\prime}(\mathrm{kPa})$ & & & \\
\hline \multirow{4}{*}{ Lianyugang Clay } & \multirow{4}{*}{ Hong et al, 2000} & \multirow{4}{*}{$\begin{array}{c}\sigma^{\prime}{ }_{v} \\
4-T e s t s\end{array}$} & $\omega=50 \%$ & 0.99 & 0.62 & 1.37 & 0.50 & 10.3 & $0.5-1600$ & Methods 2 and 3 the same \\
\hline & & & $\omega=85 \%$ & 1.28 & 0.74 & 2.31 & 0.51 & 3.80 & $0.5-1600$ & \\
\hline & & & $\omega=114 \%$ & 1.34 & 0.77 & 3.05 & 0.51 & 2.20 & $0.5-1600$ & \\
\hline & & & $\omega=142 \%$ & 1.51 & 0.83 & 3.73 & 0.51 & 1.60 & $0.5-1600$ & \\
\hline Bisaccia clay & Onofrio et al,1998 & $p^{\prime}$ & 1 & 2.71 & 1.89 & 3.01 & 50.96 & $\mathrm{~N} / \mathrm{A}$ & $50-8000$ & Methods 2 and 3 the same \\
\hline Mexico city clay & Mesri et al 1975 & $\sigma_{v}^{\prime}$ & 1 & 9.08 & 4.09 & 23.97 & 2.39 & $\mathrm{~N} / \mathrm{A}$ & $1-3000$ & Methods 2 and 3 the same \\
\hline Pleistocene stiff clay & Cotecchia et al, 1997 & $\sigma_{v}^{\prime}$ & 1 & 1.33 & 0.79 & 1.28 & 18.8 & 100 & $10-20000$ & Methods 2 and 3 the same \\
\hline Soft Louisenville & Locat et al, 1996 & $\sigma_{v}^{\prime}$ & 1 & 1.39 & 0.79 & 6.16 & 0.07 & 1.2 & $0.1-500$ & Very low stress, $p^{\prime}=0.1 \mathrm{kPa}$ \\
\hline \multirow{2}{*}{ Reconstituted Kaolin } & \multirow{2}{*}{ Shipton et al, 2012} & \multirow{2}{*}{$\sigma_{v}^{\prime}$} & \multirow[t]{2}{*}{2} & 1.28 & 0.92 & 3.33 & 1.72 & 7.80 & $1-2000$ & Methods 2 and 3 the same \\
\hline & & & & 1.23 & 0.87 & 3.46 & 1.56 & 6.65 & $1-4000$ & \\
\hline
\end{tabular}


Estimation of the compression behaviour of reconstituted clays

By MD Liu, Z Zhuang, S Horpibulsuk 


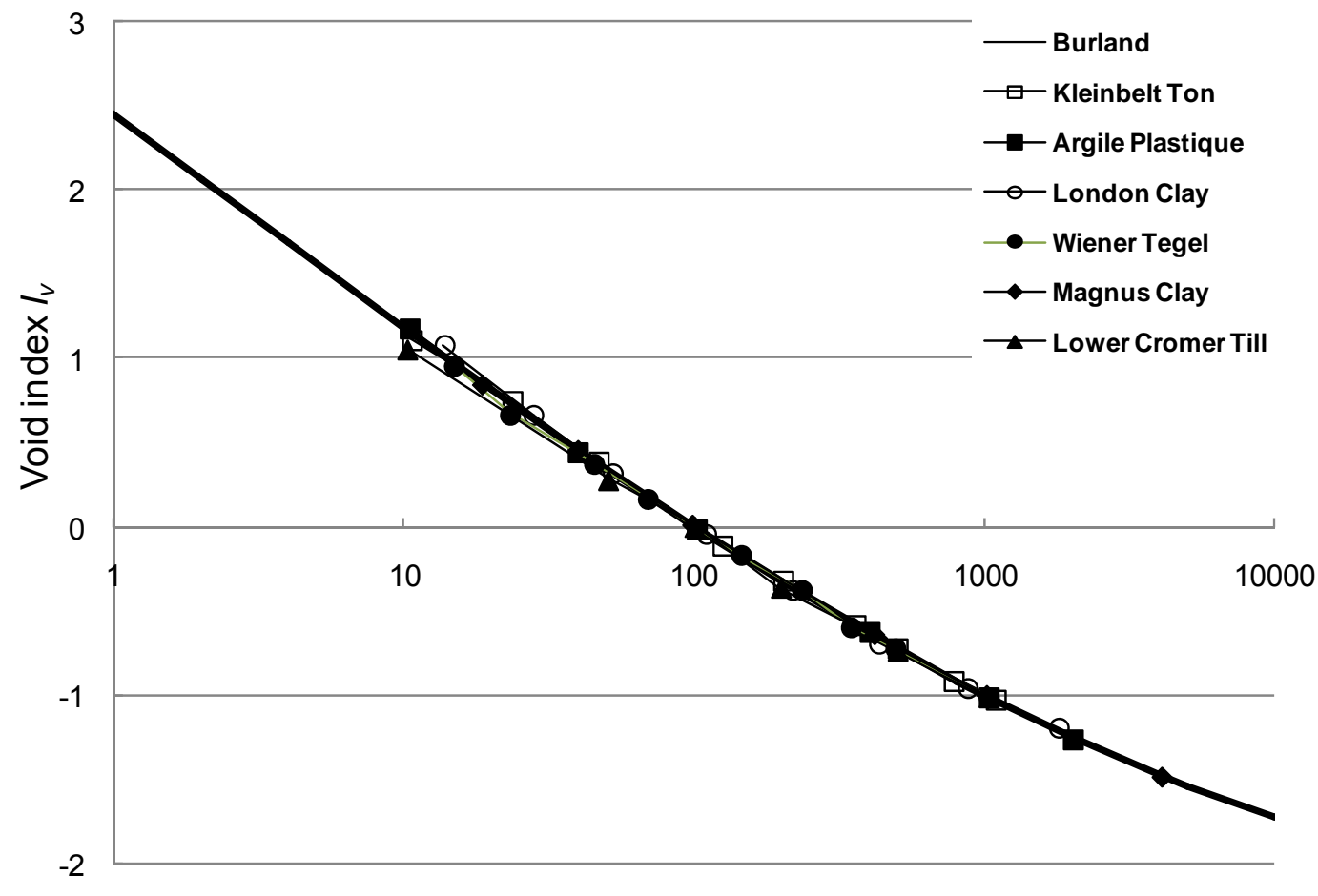

Vertical effective stress $\sigma_{v}^{\prime}(\mathrm{kPa})$

Fig. 1 Burland's equation and some experimental data (after Burland ,1990) 


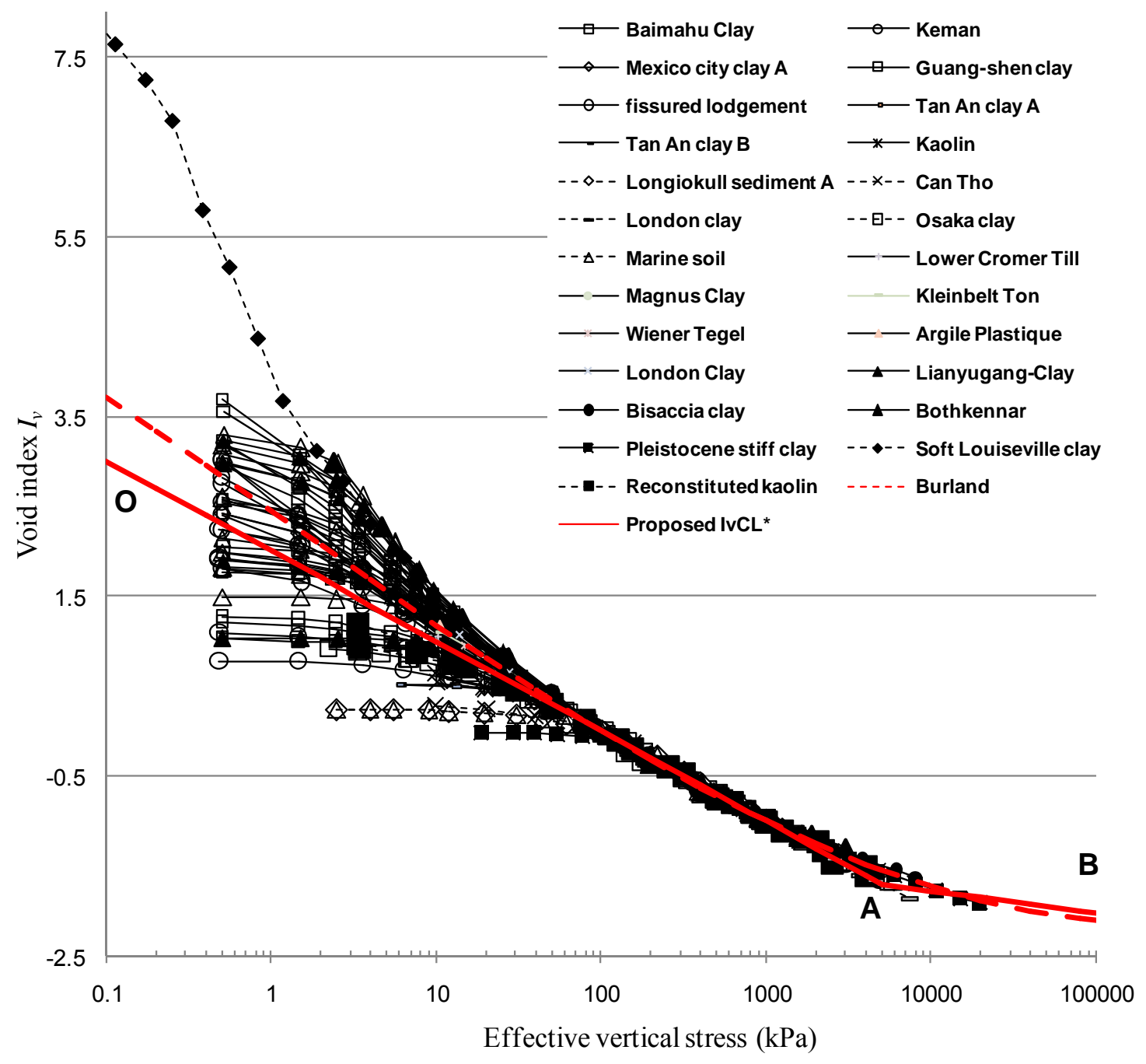


Fig. 2 A Comparison of experimental data, Burland's equation and the proposed $\mathrm{I}_{\mathrm{v}} \mathrm{CL}^{*}$ (References for data listed in Tables 1 and 2 ) 


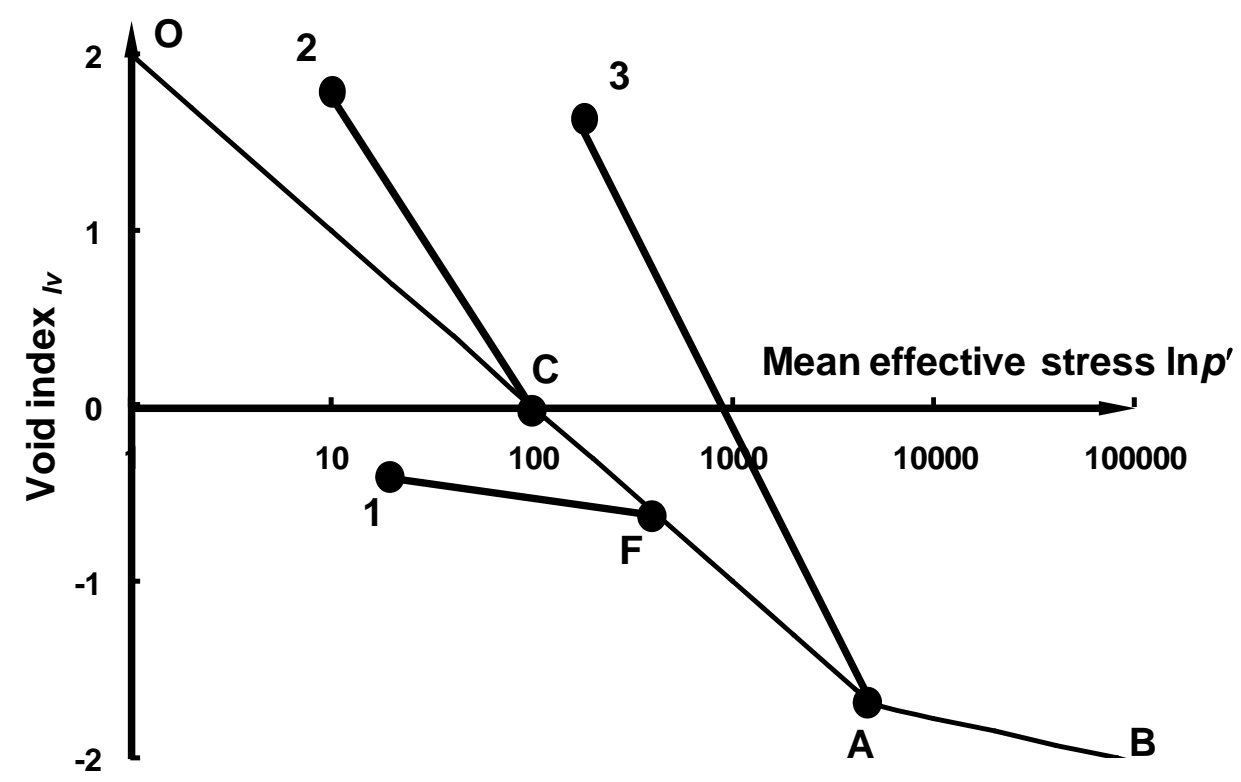

Fig. 3 Method 2 for estimating soil compression behaviour 


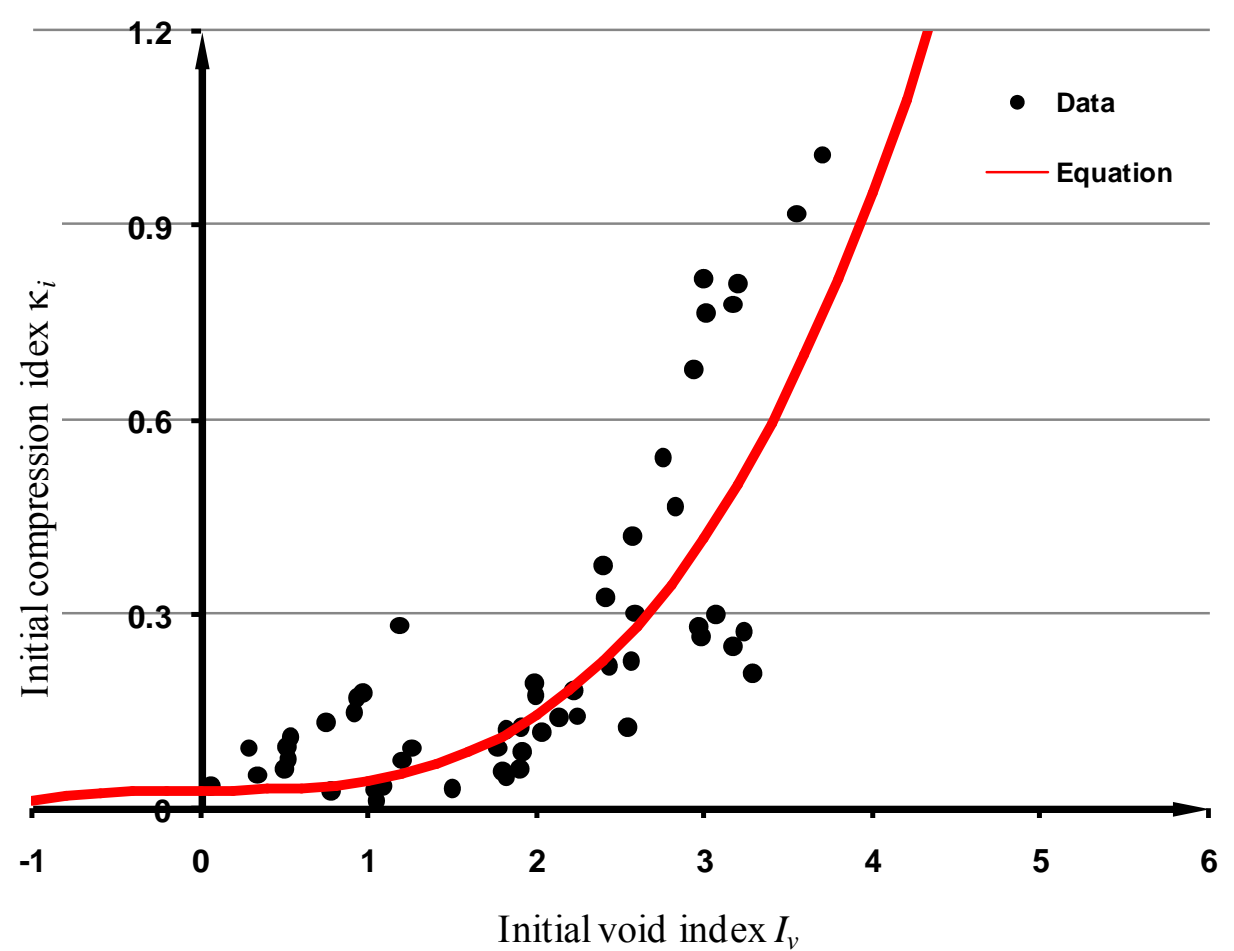

Fig. 4 Empirical equation proposed for the initial compression index 


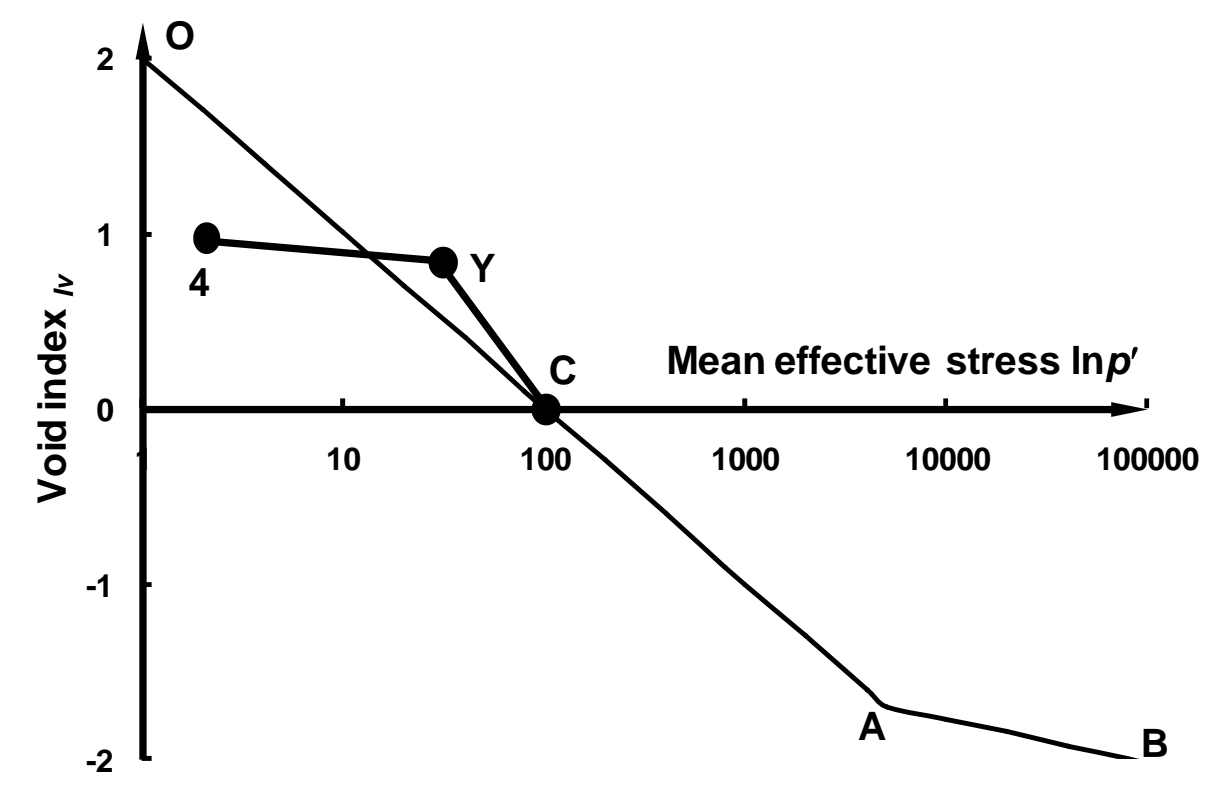

Fig. 5 Method 3 for estimating soil compression behaviour 


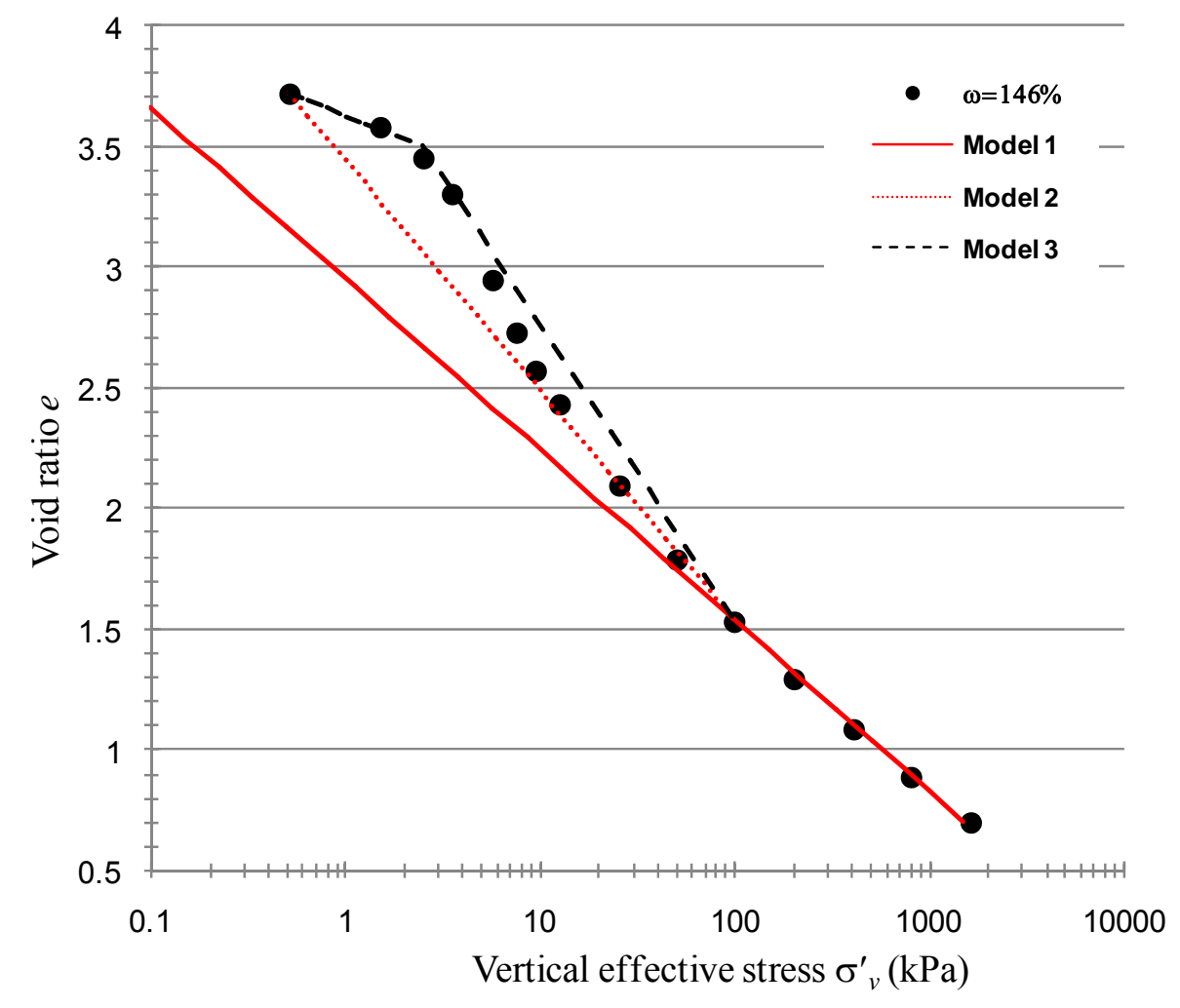

Fig. 6 Compression behavior of Lianyugang clay with $\omega=146 \%$ (Data after Hong et al, 2000) 


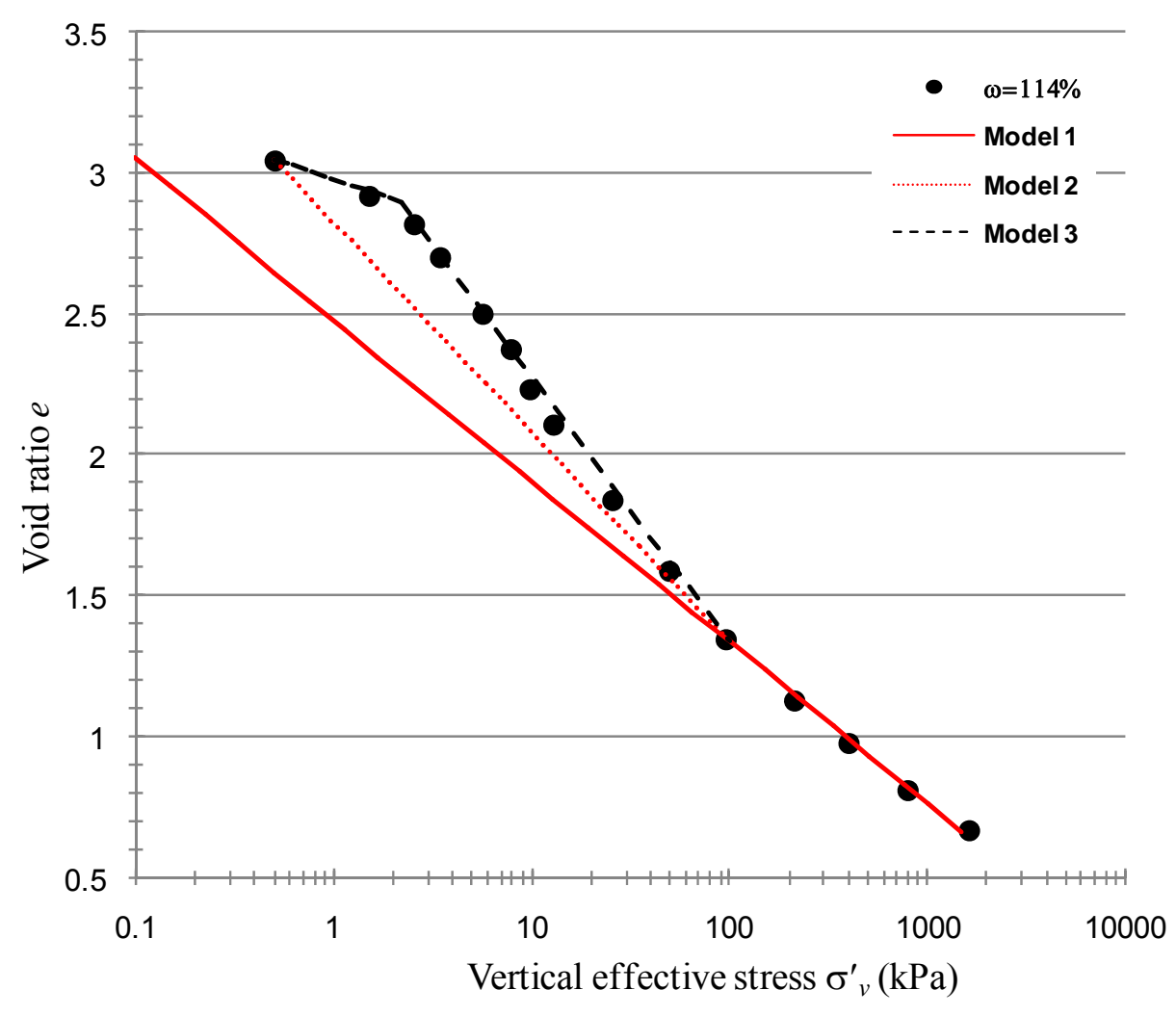

Fig. 7 Compression behavior of Lianyugang clay with $\omega=114 \%$ (Data after Hong et al, 2000) 


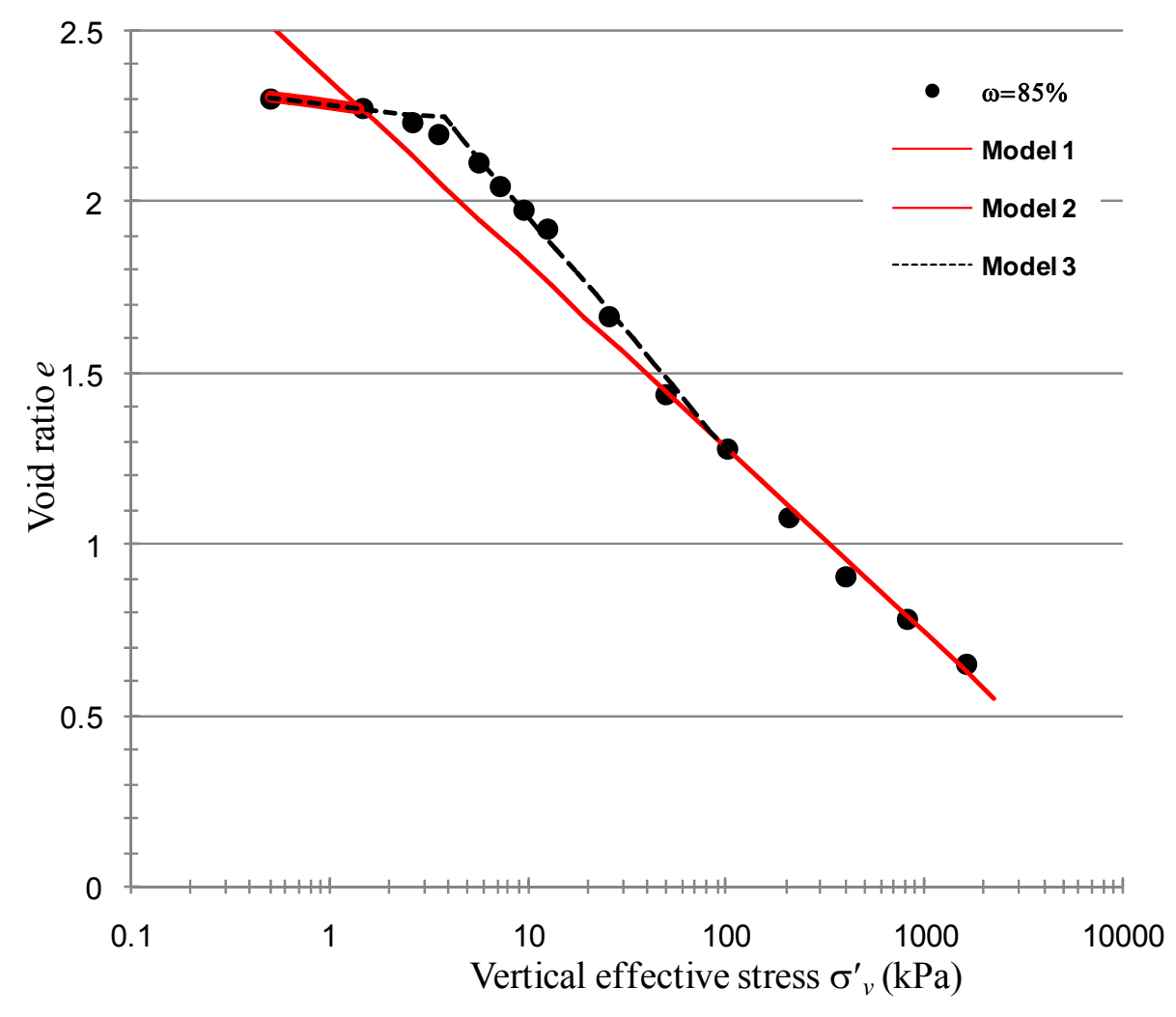

Fig. 8 Compression behavior of Lianyugang clay with $\omega=85 \%$ (Data after Hong et al, 2000) 


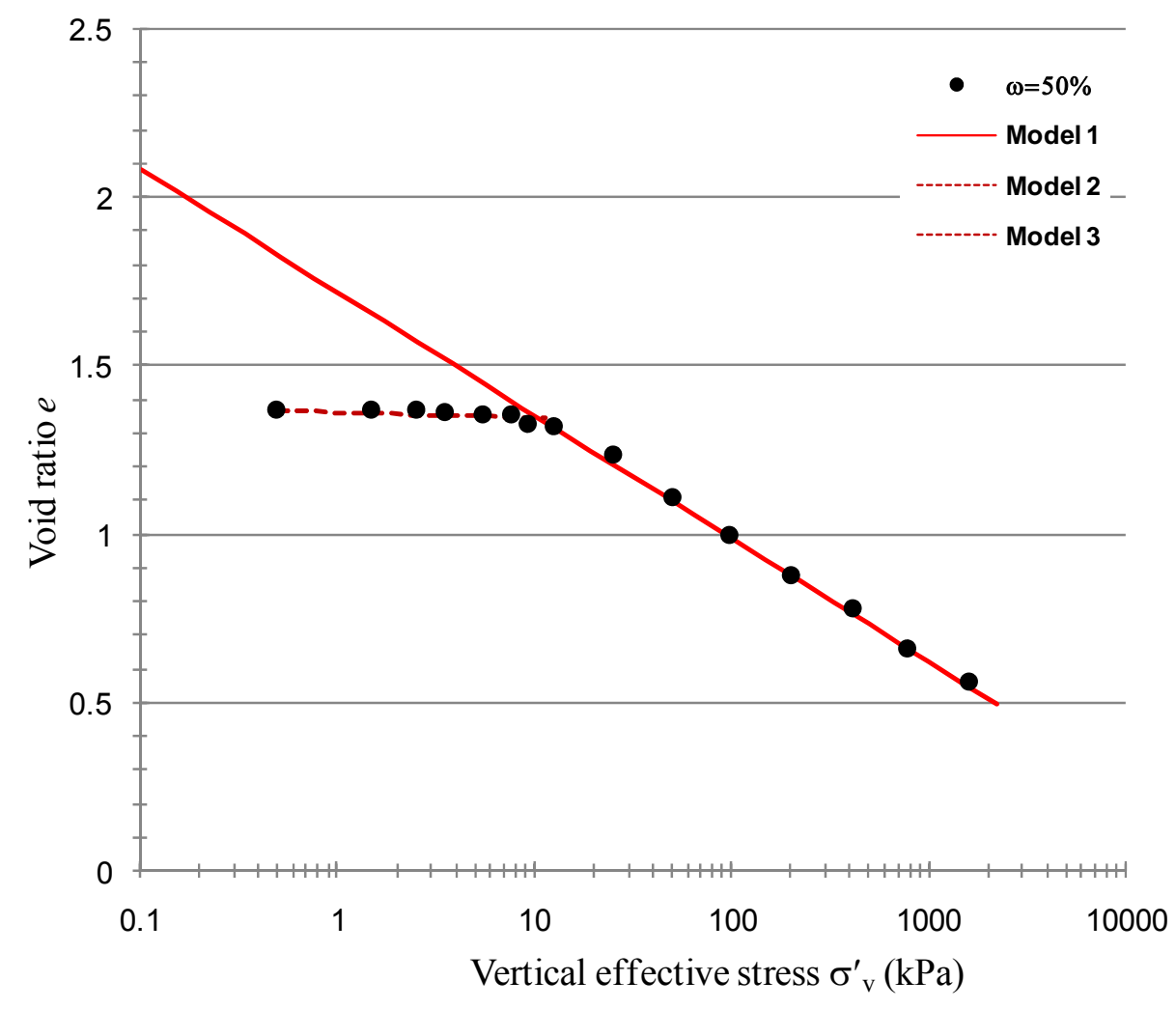

Fig. 9 Compression behavior of Lianyugang clay with $\omega=50 \%$ (Data after Hong et al, 2000) 


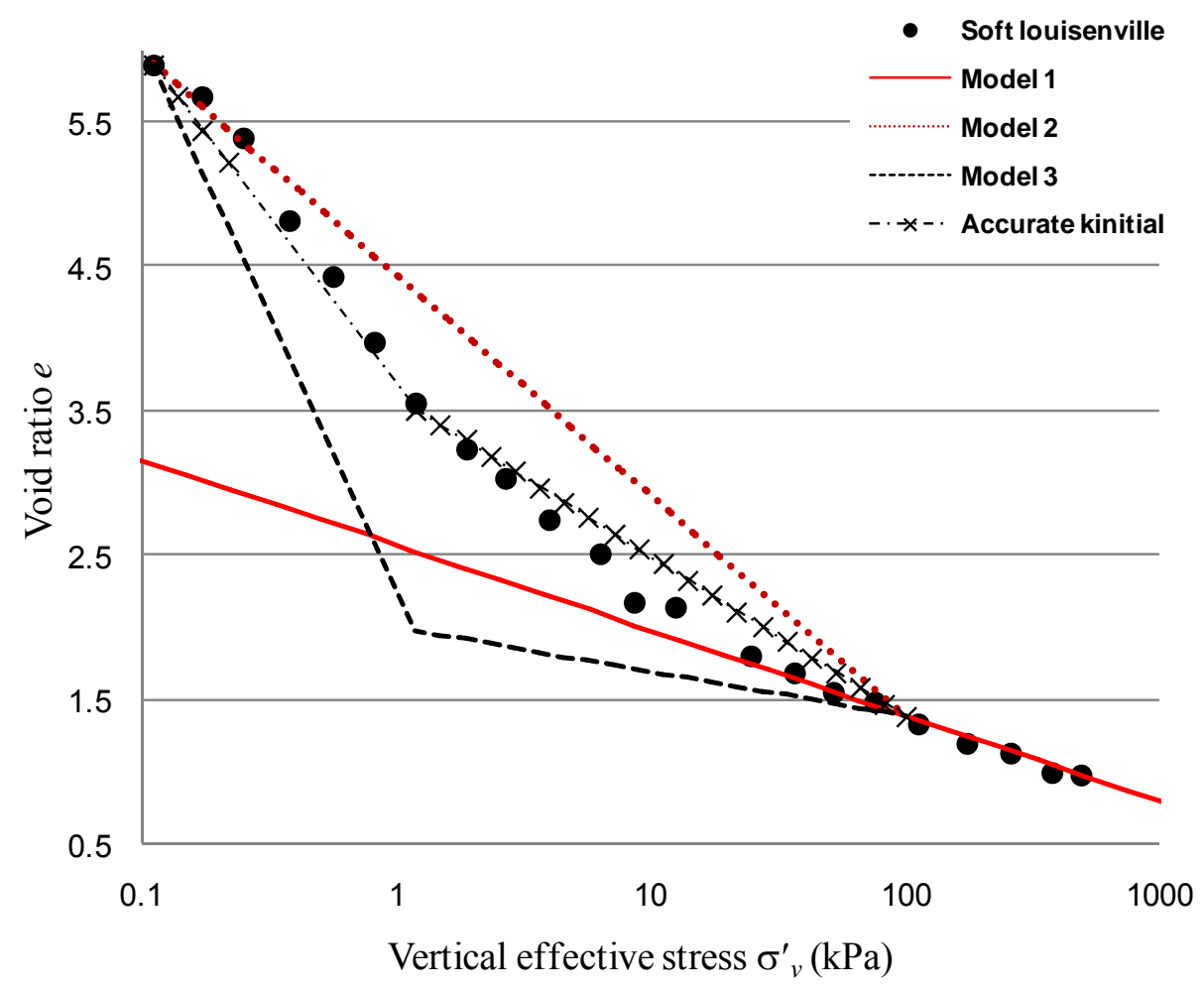

Fig. 10 Compression behavior of Soft Louisenville clay (Data after Locat et al, 1996) 


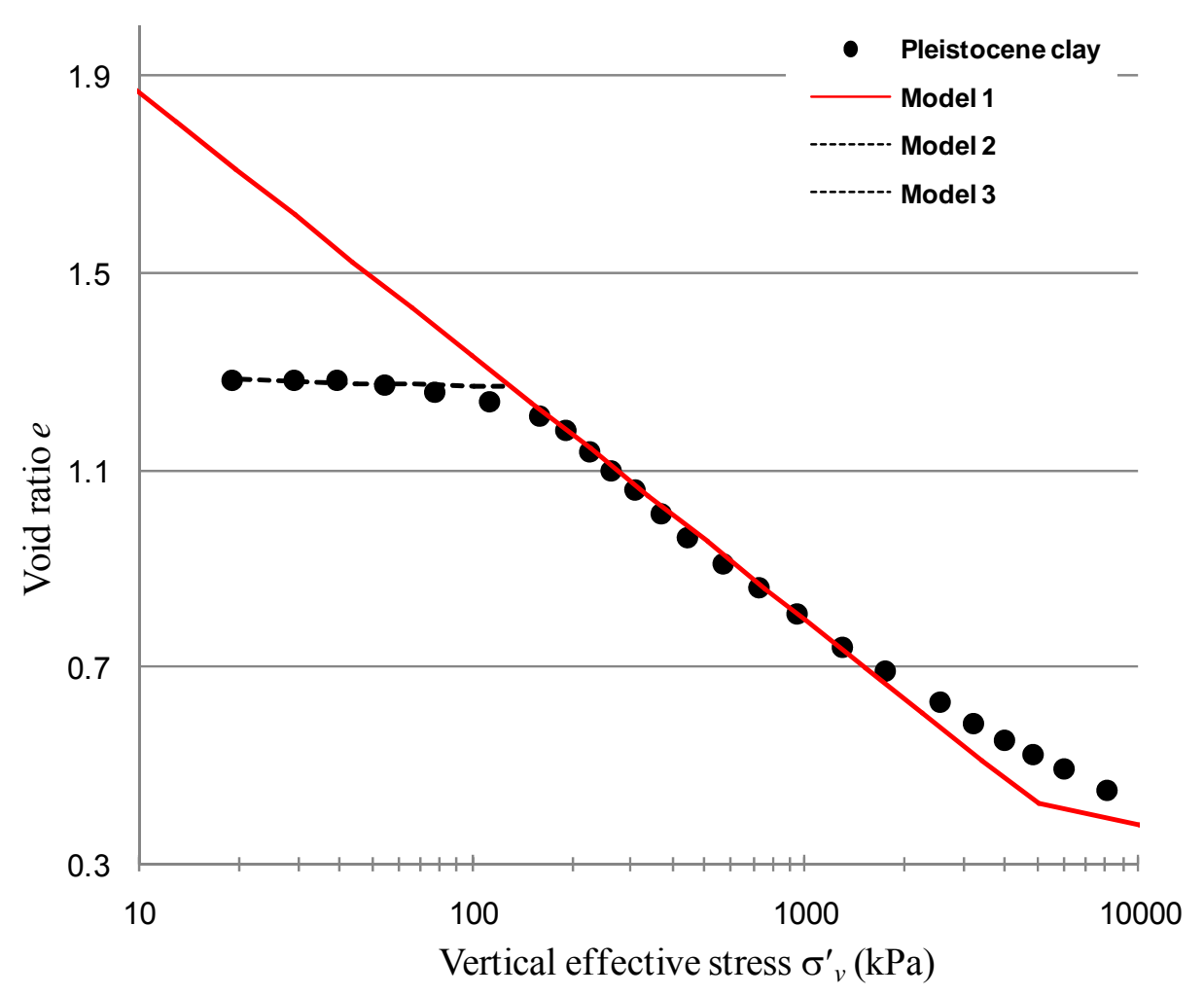

Fig. 11 Compression behavior of Pleistocene stiff clay (Data after Cotecchia et al, 1997) 


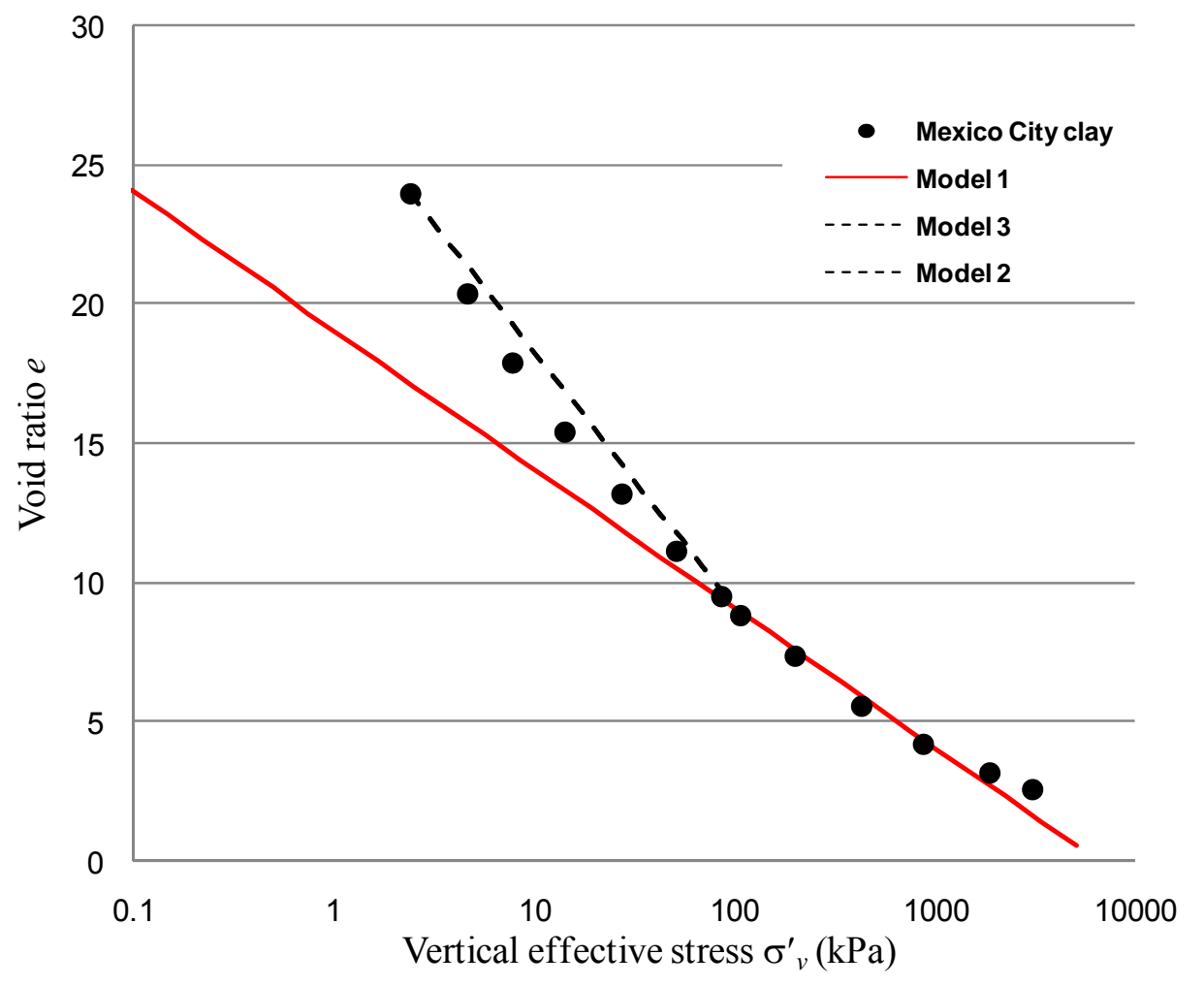

Fig. 12 Compression behavior of Bothkennar clay (Data after Burland, 1990) 


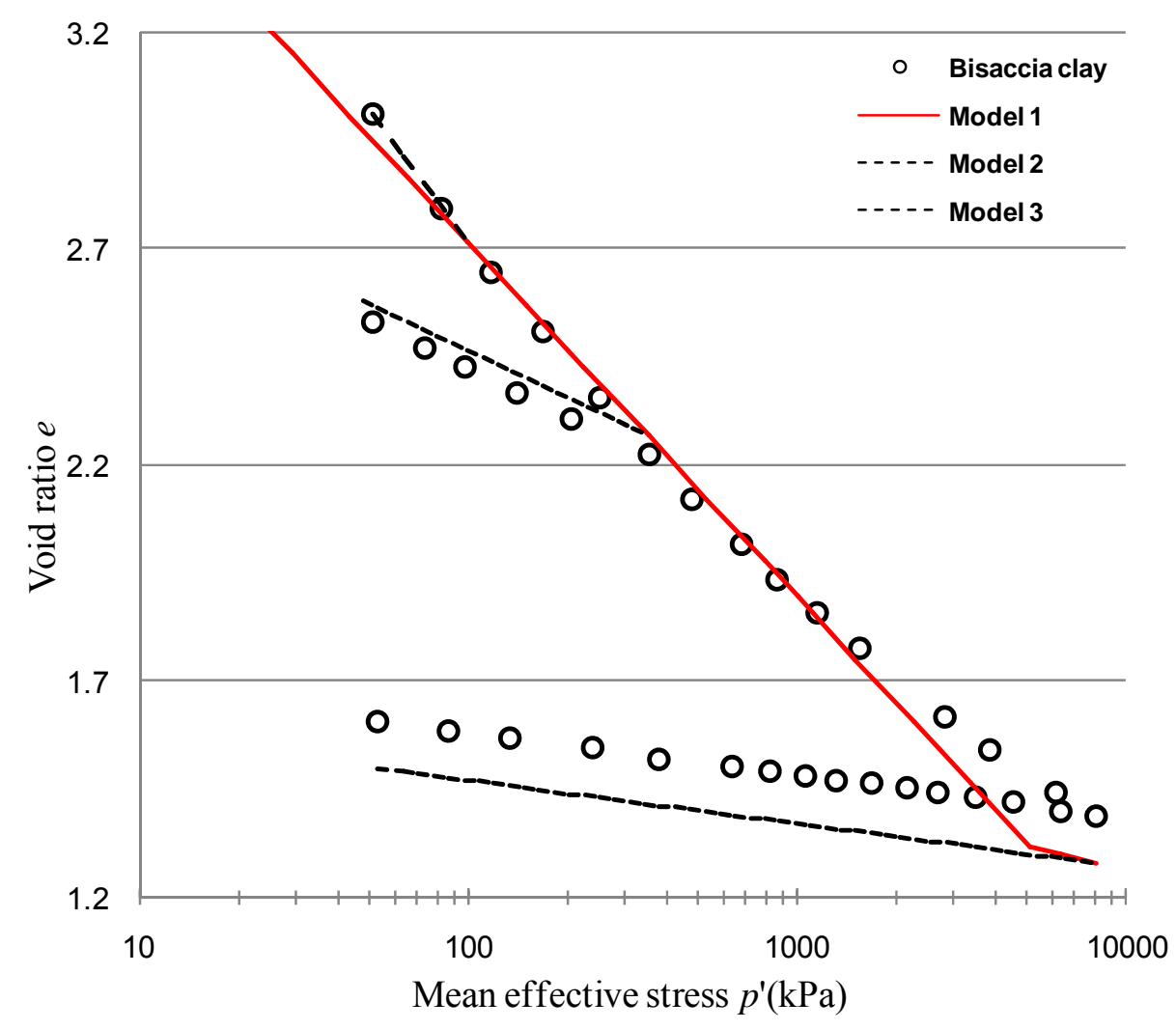

Fig. 13 Compression behavior of Bisaccia clay (Data after Onofrio et al,1998) 


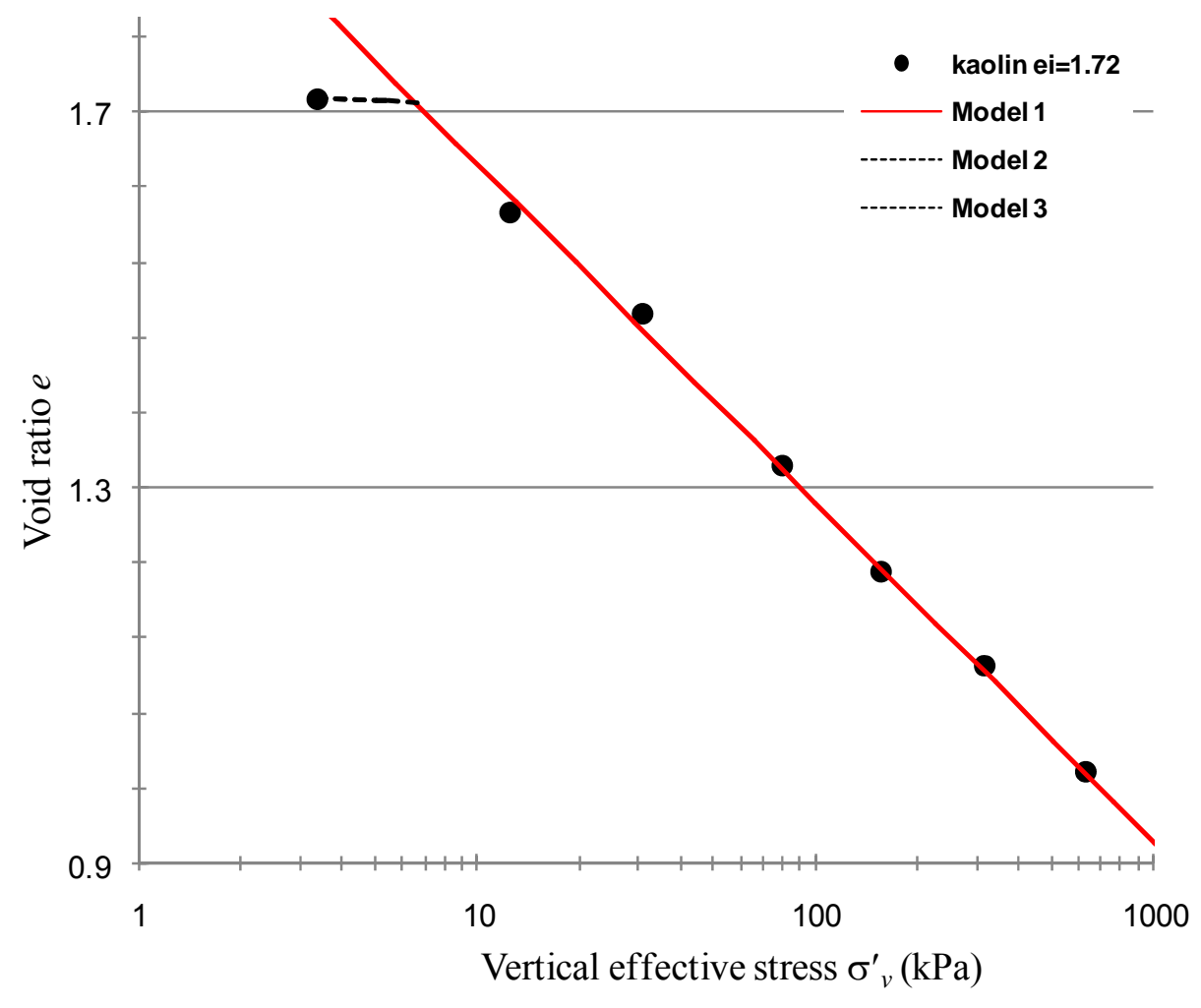

Fig. 14 Compression behavior of Kaolin with $e_{i}=1.72$ (Data after Shipton et al, 2012) 


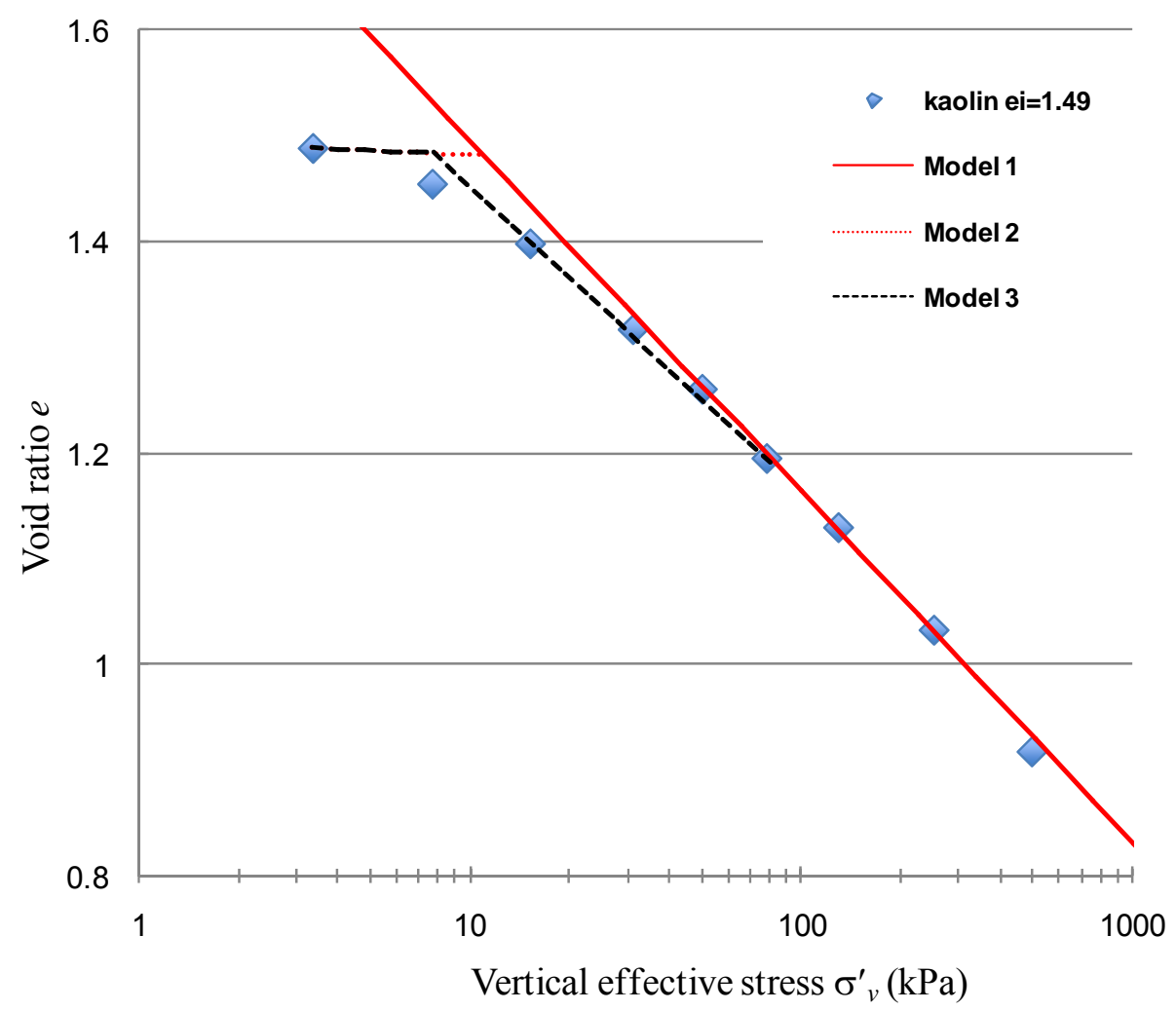

Fig. 15 Compression behavior of Kaolin with $e_{i}=1.49$ (Data after Shipton et al, 2012) 